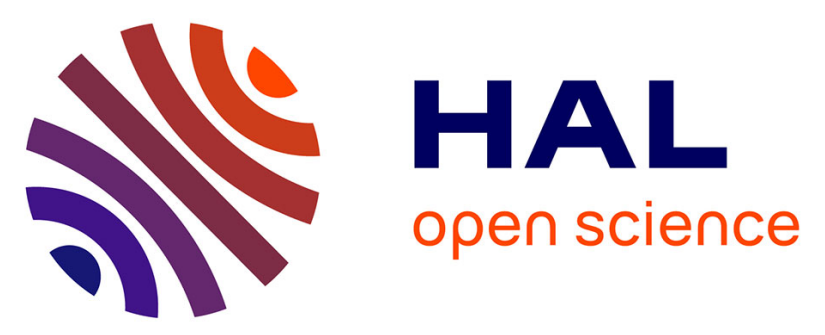

\title{
Enhanced microalgal biofilm formation and facilitated microalgae harvesting using a novel pH-responsive, crosslinked patterned and vibrating membrane
}

\author{
C. Zhao, K. Muylaert, Anthony Szymczyk, I.F.J. Vankelecom
}

\section{- To cite this version:}

C. Zhao, K. Muylaert, Anthony Szymczyk, I.F.J. Vankelecom. Enhanced microalgal biofilm formation and facilitated microalgae harvesting using a novel $\mathrm{pH}$-responsive, crosslinked patterned and vibrating membrane. Chemical Engineering Journal, 2021, 410, pp.127390. 10.1016/j.cej.2020.127390 . hal03122740

\author{
HAL Id: hal-03122740 \\ https://hal.science/hal-03122740
}

Submitted on 15 Jun 2021

HAL is a multi-disciplinary open access archive for the deposit and dissemination of scientific research documents, whether they are published or not. The documents may come from teaching and research institutions in France or abroad, or from public or private research centers.
L'archive ouverte pluridisciplinaire HAL, est destinée au dépôt et à la diffusion de documents scientifiques de niveau recherche, publiés ou non, émanant des établissements d'enseignement et de recherche français ou étrangers, des laboratoires publics ou privés. 
Enhanced microalgal biofilm formation and facilitated microalgae harvesting using a novel pH-responsive, crosslinked patterned and vibrating membrane Zhenyu Zhao ${ }^{\mathrm{a}}$, Koenraad Muylaert ${ }^{\mathrm{b}}$, Anthony Szymczyk ${ }^{\mathrm{c}}$, Ivo F.J. Vankelecom ${ }^{\mathrm{a}}$ ${ }^{a}$ Membrane Technology Group (MTG), Division cMACS, Faculty of Bio-Science Engineering, KU Leuven, Celestijnenlaan 200F, PO Box 2454, 3001 Leuven, Belgium

${ }^{\mathrm{b}}$ Lab Aquatic Biology, Microbial en Molecular Systems, KU Leuven KULAK, E. Sabbelaan 53, B-8500 Kortrijk, Belgium

${ }^{c}$ Univ Rennes 1, CNRS, ISCR (Institut des Sciences Chimiques de Rennes)-UMR 6226, F-35000, Rennes, France

\section{Abstract:}

Harvesting efficiency is one of the key issues restricting the further commercialization of microalgae. Traditional biofilm studies only tend to focus on enhancing biofilm formation, while neglecting the subsequent harvesting of the biofilm. In this study, a win-win strategy for high-density microalgal cultivation and low-cost harvesting through biofilm cultivation on a pH-responsive, charge-switchable, patterned membrane was investigated using a polyethylenimine (PEI)-crosslinked polyvinylidene fluoride (PVDF) membrane. The patterned membranes were prepared by spray-modified non-solvent induced phase inversion, and the effect of pattern height on biofilm formation and microalgal harvesting was investigated. The PEI-crosslinked PVDF membrane surface was positively charged below $\mathrm{pH} 8$ and negatively charged above $\mathrm{pH} 9$, resulting in a higher attractive energy 
below pH 8 and a repulsive energy above pH 9 according to the extended Derjaguin, Landau, Verwey, Overbeek model. Patterning of these membranes increased the active area for microalgal attachment, and created a low-shear area in the valleys that prevents early detachment of microalgal cells. Membranes with a higher pattern height resulted in faster biofilm development and increased final biomass accumulation. Low-energy membrane vibration was applied to enhance cell detachment. $\mathrm{pH}=7$ was found to be the optimal $\mathrm{pH}$ for enhanced microalgal biofilm formation on PEI-crosslinked patterned membranes, and a switch to $\mathrm{pH}=10$ was best for microalgal harvesting.

Key words: Biofilm; Patterned membrane; Computational fluid dynamics; XDLVO; Interaction energy; Membrane development

\section{Introduction}

Microalgae are a highly productive, novel biomass resource which gained widespread attention as a third-generation biofuel feedstock, as well as for the production of high value-added bioproducts (e.g. protein, polysaccharides, poly-unsaturated fatty acids and pigments) [1]. Microalgae are currently cultivated as relatively dilute suspensions of small cells ( 0.5 to 5 dry matter/L). This results in a high water requirement and a high energy demand to remove all water during harvesting [2]. The options for harvesting include centrifugation, membrane filtration and sedimentation. Centrifugation is most common for harvesting microalgae, but the energy consumption is high [2]. Flocculation followed by sedimentation is considered to be the cheapest and easiest method, but chemicals needed to induce flocculation 
contaminate the harvested biomass [3, 4]. Membrane separations achieve a high harvesting efficiency with a lower energy consumption compared to centrifugation. However, fouling is the preponderant problem restricting the filtration process $[2,3]$.

Microalgal biofilms have been proposed as an alternative cultivation strategy in the last decade. By growing microalgae as a thin but concentrated layer of cells on a fixed substrate, the water requirement and energy demand for harvesting can be strongly reduced [5]. In such aquatic biofilms, microalgal cells adhere onto a solid substrate using a holdfast or by producing a mucilage layer [6]. The formation of these biofilms is often initiated by a consortium of microalgal cells and bacteria that are connected by an extracellular polymeric matrix [7]. These biofilms gradually grow thicker as microalgae near the surface of the biofilm carry out photosynthesis and assimilate nutrients and $\mathrm{CO}_{2}$ from the medium [8]. Such an immobilized cultivation of microalgae in biofilms allows for a more efficient use of sunlight through a light dilution approach, resulting in a higher areal productivity compared to cultivation of microalgae in suspension [9]. Microalgal biofilms have been used for wastewater treatment and displayed an advanced nutrient removal compared with other technologies, such as ecological floating beds, constructed wetlands or aquatic macrophyte ponds, especially at conditions of low nutrient concentration [10-13].

Microalgal biofilms should be firmly attached to the solid substrate to avoid losses of biomass [13]. Turbulence of the liquid surrounding the biofilm should be managed carefully as sufficiently high shear stress is required to enhance nutrient transfer to the biofilm, while high shear stress can also lead to microalgal detachment $[14,15]$. 
Several approaches have been explored to optimize microalgal biofilm adhesion onto a solid substrate. In general, substrates with rough surface and/or porous structure facilitate the microalgal biofilm attachment [13]. For example, Chlorococcum sp. adhesion was tested on nine different materials and microalgal biofilm formation was optimal on a glass-fiber-reinforced plastic with concave structure [16]. As opposed to materials such as glass or natural or synthetic fibers, membranes can be considered as an ideal substrate for biofilms formation due to their large surface area and tunable surface properties, such as pore size and porosity [11, 17, 18]. Another advantage of using membranes is that pores in the membrane can be used to supply water, mineral nutrients and/or $\mathrm{CO}_{2}$ [19]. Modifying surface roughness and topography can further enhance biofilm formation. A stainless steel mesh modified polytetrafluoroethylene (PTFE) membrane with a high surface roughness showed an almost twice as high areal biomass concentration of Scenedesmus obliquus (S. obliquus) biofilm when compared to a smooth PTFE membrane [20]. Besides, S. obliquus biomass production was $14.3 \%$ higher on a V-groove patterned membrane compared to a flat membrane [14].

In addition to surface roughness, creation of surface charge is another approach to enhance biofilm adhesion. Previous studies showed that the inoculation time of $S$. obliquus and Ankistrodesmus falcatus mixed biofilms was significantly reduced from $4 \mathrm{~h}$ to $1.5 \mathrm{~min}$ by changing microalgal surface charges [5]. Polyethylenimine (PEI) is a biocompatible polymer that is positively charged at low $\mathrm{pH}(<7)$. This positive charge facilitates cell adhesion onto various surfaces [21, 22]. For instance, viscose 
biosensors are treated with PEI to enhance Escherichia coli biofilm formation [23]. In microbial fuel cells, the anode is often treated with PEI to enhance microbial biofilm formation, resulting in a higher power density of the fuel cell $[24,25]$.

Most studies on microalgal biofilms only focused on enhancing the formation of the biofilm, while neglecting the final and at least as crucial biofilm detachment for microalgal harvesting. In addition, understanding the microalgal attachment/detachment mechanisms is also limited. Biofilm detachment highly relies on the hydrodynamic conditions as well as the biological/chemical interaction between the biofilm and the solid surface [26, 27]. Using hydrodynamic shear, physical scraping or biological/chemical treatment to detach the biofilm results not only in a high cost in the form of energy or chemicals, but also risks damaging the microalgal cells, resulting in a low quality of the biomass. Often, harvesting is incomplete, resulting in significant waste [11]. An ideal substrate should be able to strongly immobilize microalgal cells during the growth period, while releasing them easily during the harvesting stage. Microalgal cells are encapsulated in a shell of sulphated polysaccharide, carboxylic acids, uronic acids or acidic sugars to protect against environmental stress, rendering microalgal cells a negatively charged surface $[2,28]$. Therefore, it is hypothesized that the adhesion and detachment of microalgal cells can be realized by controlling the carrier surface charge which can generate electrostatic attraction and repulsion under positive and negative charges, respectively. The physico-chemical interaction between a solid surface and microalgal cells in an aqueous solution is determined by attractive Lifshitz-van der Waals (LW), Lewis 
acid-base $(\mathrm{AB})$ and repulsive electrostatic double layer (EL) interactions and can be simulated using the extended Derjaguin, Landau, Verwey, Overbeek (XDLVO) model [29].

pH-responsive, charge-switchable modifications have been used in many fields, including flocculation, drug delivery, membrane separation, etc. [30-32]. Imidazole and amine groups are most commonly used, which can convert charge by protonation and de-protonation at different $\mathrm{pH}[33,34]$. However, the protonation of the imidazole group occurs at a $\mathrm{pH}<6$, which is not always suitable for microalgal growth $[35,36]$. A recent study reported that PEI containing membranes showed a positive charge at $\mathrm{pH}<8$, and a negative one at $\mathrm{pH}>8.5$ [37]. This $\mathrm{pH}-$ range is suitable for typical microalgal growth. In membranes, PEI surface modification has been used to improve separation of pharmaceuticals but not to enhance biofilm formation.

In this study, porous PVDF membranes with different pattern heights were prepared using a recently developed one-step method (i.e. phase inversion by spraying of the non-solvent on the cast patterned film [38, 39]). The membranes were subsequently cross-linked with PEI to introduce a $\mathrm{pH}$-dependent charge on the membranes using a one-step crosslinking method. These PEI-cross-linked patterned PVDF membranes were for the first time applied for microalgal biofilm production and tested for enhanced biofilm attachment during the growth stage and facilitated biofilm release during harvesting, thanks to their charge-switchable properties over the $\mathrm{pH}$ range 5 to 10. The deposition of microalgal cells onto the membranes was investigated using dead-end filtration. Cell detachment was achieved using an energy-efficient 
magnetically induced membrane vibration (MMV). Microalgal biofilms were cultivated at different $\mathrm{pH}$ levels and the growth conditions were monitored. The interaction between the microalgal cells and the PEI-modified membranes at different $\mathrm{pH}$ levels was modeled using the XDLVO theory. Finally, the fluid behavior near the membrane surface was studied using computational fluid dynamics (CFD).

\section{Materials and methods}

\subsection{Cultivation of microalgae}

Desmodesmus sp. (isolated and purified from Hainan island, China) [40-42] was cultivated in a $30 \mathrm{~L}$ column photobioreactor (PBR) with 25 L BG-11 medium and illuminated by two fluorescent lights on both sides [43]. The microalgae were cultivated at $22 \pm 1{ }^{\circ} \mathrm{C}$, and kept under continuous air aeration of $15 \mathrm{~L} / \mathrm{min}$ with a constant illumination intensity of $100 \mu \mathrm{mol}$ photons $/ \mathrm{m}^{2} \mathrm{~s}$ at the surface of the reactor. Dry weight was determined gravimetrically after 10 days of cultivation by filtrating a known volume of microalgae culture broth onto a pre-weighed $0.1 \mu \mathrm{m}$ filter. The final dry weight was $0.82 \pm 0.03 \mathrm{~g} / \mathrm{L}$.

\subsection{Membrane preparation}

The patterned membranes were prepared using a modified one-step phase inversion by spraying method $[39,40]$. An extra sprayer was installed on the casting machine (Braive Instruments, Belgium), which allows deionized water to be sprayed on the cast film right after passage of the casting knife to realize immediate phase inversion and maintain the surface pattern on the freshly shaped membrane surface $[38,44]$. PVDF (Mw 543 kDa, Sigma-Aldrich, Belgium) with a concentration of 20w\% was 
dissolved in N,N-dimethylformamide (DMF, 99.8\%, Acros organics, Belgium) using polyvinylpyrrolidone (PVP, Mw 10 kDa, Sigma-Aldrich, Belgium) as pore-forming agent in concentrations of $6.7 \mathrm{w} \% .1 \mathrm{w} \%$ deionized water was added into the casting solution to accelerate the phase inversion process. The casting solution was stirred at $80 \mathrm{rpm}$ at $65{ }^{\circ} \mathrm{C}$ for $48 \mathrm{~h}$ and then degassed overnight. The solution was cast on a glass plate at a speed of $2.25 \mathrm{~cm} / \mathrm{s}$ using the rectangle-shaped patterned knife with a wet thickness of $200 \mu \mathrm{m}$ (measured from the plate to the bottom of the knife patterns), after which the cast film was immediately immersed into deionized water $\left(21^{\circ} \mathrm{C}\right)$ to complete the phase inversion. To evaluate the effect of patterning on microalgal biofilm attachment, a flat membrane was made using a conventional flat casting knife with the same wet thickness and direct immersion in the coagulation bath after spraying.

The rectangle-shaped patterned knives were made using a 3D-printer. To investigate the effect of pattern height, two patterned knives with different pattern heights $(500 \mu \mathrm{m}$ and $1000 \mu \mathrm{m})$ and the same inter-pattern distance $(500 \mu \mathrm{m})$ were used.

\subsection{Crosslinking}

The PVDF-crosslinking by PEI $[45,46]$ is schematically shown in Fig. 1a. The membranes were immersed in a closed beaker containing the crosslinking solution, which consisted of $4.5 \mathrm{w} \% \mathrm{NaOH}$ (Sigma-Aldrich, Belgium) and $25 \mathrm{w} \%$ branched polyethylenimine (PEI, Mw 25000 Da, Sigma-Aldrich, Belgium). The mixture was vigorously stirred for $1 \mathrm{~h}$ under room temperature to fully dissolve $\mathrm{NaOH}$ and PEI. 
After $24 \mathrm{~h}$ crosslinking, the membranes turned black (Fig. 1b and 1c) and were washed using deionized water to remove the residual crosslinking solution. The membranes were stored in deionized water for further application.

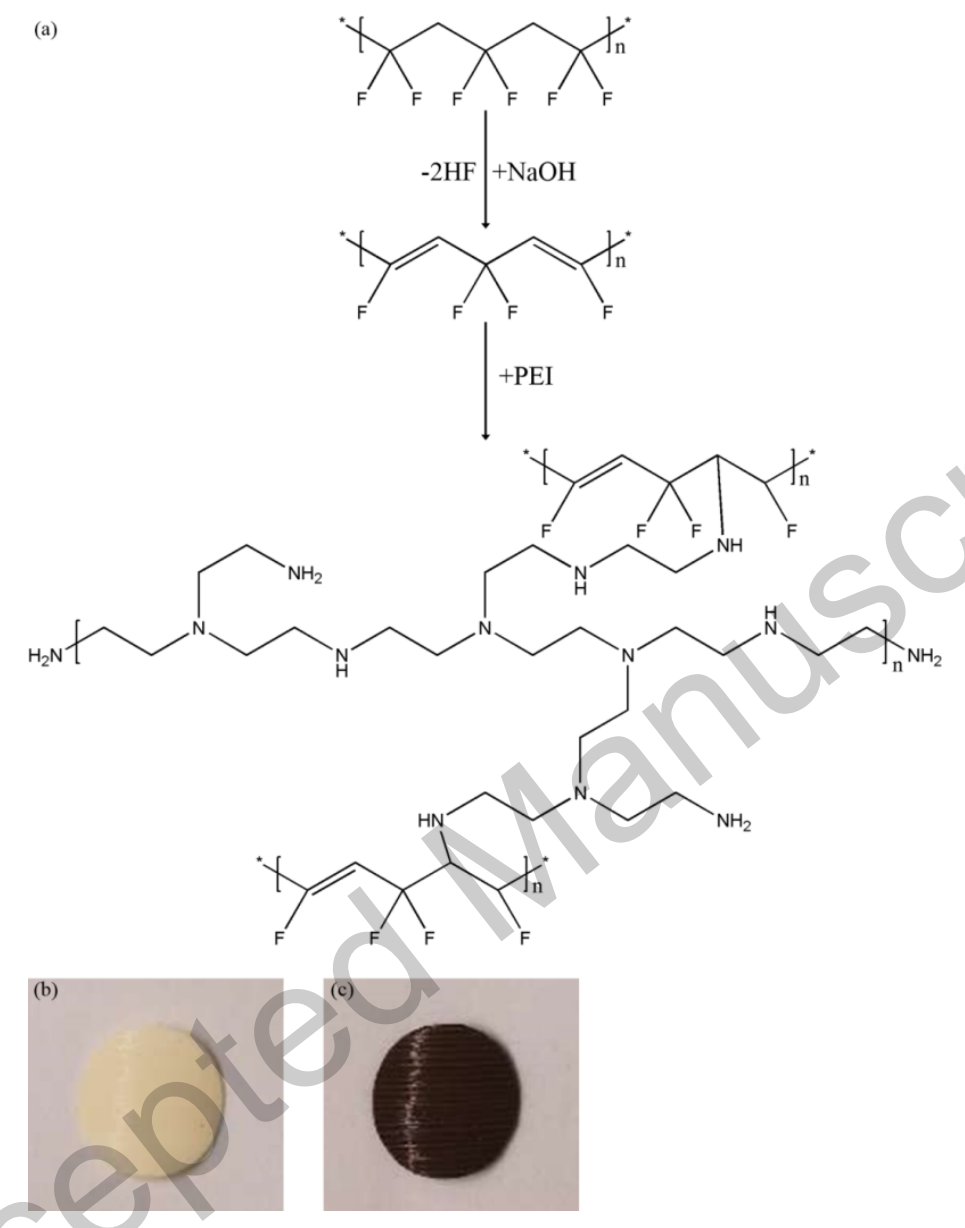

Fig. 1 (a) Schematic diagram of the dehydrofluorination and amine-based crosslinking reaction of PVDF and visual appearance of the membrane (b) before and (c) after crosslinking.

\subsection{Microalgal biofilm initial attachment strength analysis}

Five different membranes were used to test the microalgal biofilm formation: a crosslinked patterned membrane with $500 \mu \mathrm{m}$ pattern height (CL-PM500) and one with $1000 \mu \mathrm{m}$ pattern height (CL-PM1000), a patterned membrane with $500 \mu \mathrm{m}$ pattern height without crosslinking (PM500), a crosslinked flat membrane (CL-FM) 
and a flat membrane without crosslinking (FM).

The membranes were first placed in a high-throughput dead-end filtration system (HTML, Belgium) [2] containing 8 membrane coupons with a $2.27 \mathrm{~cm}^{2}$ filtration active area each. To investigate the effect of $\mathrm{pH}$ on microalgae initial attachment, the microalgal broth was adjusted to different $\mathrm{pH}$ values $(5,6,7,8,9$ and 10) and poured into the filtration system feed compartment to let broth and membrane stabilize for 30 min for (i.e. to complete protonation or deprotonation of the membrane surfaces). The microalgal broth was homogenized under $350 \mathrm{rpm}$ stirring. Filtration was performed under 10 bar, and $15 \mathrm{~mL}$ microalgal broth was filtrated through each membrane to complete the first deposition. After that, three replicate membranes with deposited microalgae were used for gravimetrical analysis of the biomass that was initially deposited on the membrane surface, and the biomass concentration of initial deposition was determined based on the biomass dry weight per $\mathrm{m}^{2}$ membrane (Eq. (1)).

$C_{a}=\frac{M_{a m}-M_{m}}{A_{m}}$

where $C_{a}$ is the areal dry microalgal biomass density $\left(\mathrm{g} / \mathrm{m}^{2}\right) ; M_{a m}$ the dry mass of membrane and microalgae $(\mathrm{g}) ; M_{m}$ the dry mass of membrane $(\mathrm{g}) ; A_{m}$ the apparent surface area of membrane $\left(\mathrm{m}^{2}\right)$.

After this first deposition, the wet membranes with freshly deposited microalgae were potted in a module with 5 coupons and the same active area each (Fig. 2a and 2b). The prepared module was installed in an MMV system (Fig. 2c), as described before [2]. The MMV system moves the module up and down with a certain 
frequency and amplitude using a sinusoidal vibration pattern. The patterned membranes were fixed with the surface pattern lines perpendicular to the moving direction. The module was immersed into deionized water with corresponding $\mathrm{pH}$. The frequency and amplitude were converted to a shear rate value to further analyze the flow near the oscillating membrane surface. The maximal shear rate was calculated according to a previous study [47, 48] using Eq. (2):

$\tau_{\max }=\frac{\alpha \epsilon^{1.5}}{2 v^{0.5}}$

where $\tau_{\max }$ is the maximal shear rate $\left(\mathrm{s}^{-1}\right) ; \alpha$ is amplitude $(\mathrm{m}) ; C$ is the frequency $(\mathrm{rad} / \mathrm{s})$ and $v$ is the kinematic viscosity $\left(1.3 \times 10^{-6} \mathrm{~m}^{2} \mathrm{~s}^{-1}\right.$ at $\left.20^{\circ} \mathrm{C}\right)$.
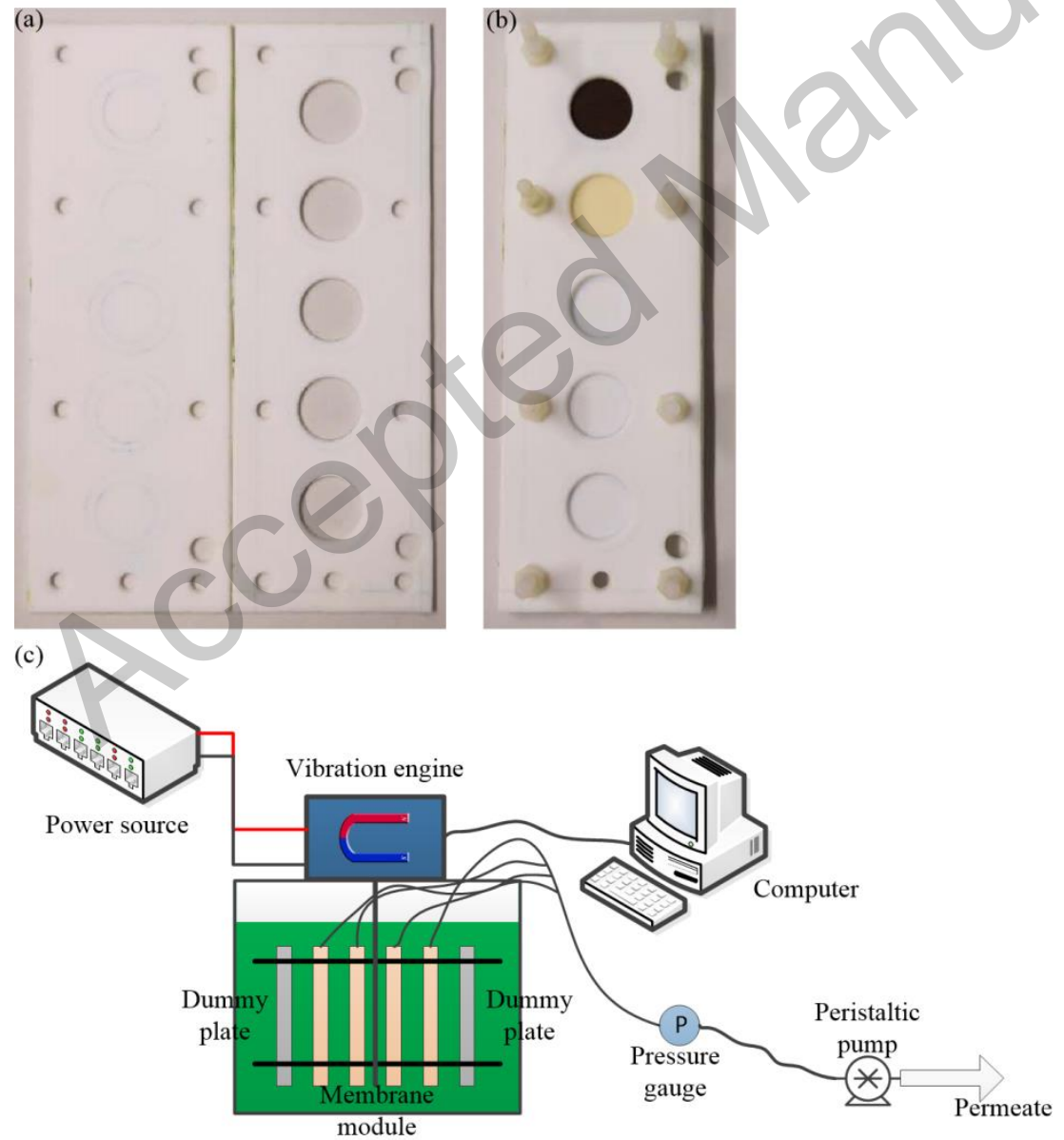

Fig. 2 Pictures of the membrane module (a) before and (b) after potting membranes, and (c) the magnetically induced membrane vibration system 
(MMV).

The corresponding Reynolds (Re) number in the MMV system was calculated using Eq. (3):

$R e=\frac{\rho U_{\max } L}{\mu}$

where $\rho$ is the broth density $\left(\mathrm{kg} / \mathrm{m}^{3}, 1024 \mathrm{~kg} / \mathrm{m}^{3}\right) ; U_{\max }(=\alpha \times C \mathrm{~m} / \mathrm{s})$ the maximum fluid velocity on the membrane surface; $L$ the length scale $(\mathrm{m}) ; \mu$ the apparent viscosity $(\mathrm{Pa} / \mathrm{s}, 0.0018 \mathrm{~Pa} / \mathrm{s})[49]$.

To prevent excessive microalgae detachment from the membrane surface, the frequency and amplitude were set at $1 \mathrm{~Hz}$ and $5 \mathrm{~mm}$ (with a corresponding shear rate of $34.5 \mathrm{~s}^{-1}$ ), respectively, to generate a relatively low shear according to a previous study [2]. After 10 min vibration at $\mathrm{pH}$ 7, the membranes with remaining microalgae were taken for gravimetric analysis of the areal microalgal biomass density using Eq. (1) to determine the initial attachment of the microalgae. The initial detachment was calculated using Eq. (4). A lower initial detachment corresponds to a stronger initial attachment.

$R_{d}(\%)=\frac{M_{d}-M_{a}}{M_{d}} \times 100$

where $R_{d}$ is the microalgal initial detachment; $M_{d}$ the dry mass of initially deposited microalgae $(\mathrm{g}) ; M_{a}$ the dry mass of initially attached microalgae (g) (i.e. after vibration, the remained microalgal mass).

\subsection{Microalgal biofilm growth}

To evaluate the growth of the biofilm, after initial attachment (without drying) at $\mathrm{pH}$ 7, 6 modules with microalgae attached membranes were respectively immersed 
into 6 1.2 L PBRs which contained 1 L BG-11 medium each at different pH-values (5, 6, 7, 8, 9 and 10). Each membrane was replicated 3 times. The culture conditions in the PBRs (temperature, light and aeration) were the same as for the $25 \mathrm{~L}$ PBR used for production of Desmodesmus sp.. Microalgal biofilm growth was under static condition for 14 days. The modules were vertically immersed into PBRs, and the membrane surface faced the light for microalgal biofilm growth. The aeration tube was positioned behind the module to reduce bubble scouring. The $\mathrm{pH}$ of the medium was adjusted every day by addition of $0.5 \mathrm{M} \mathrm{HCl}$ or $\mathrm{NaOH}$ solutions to guarantee the constant $\mathrm{pH}$-value during the whole growth period. The volume of the reactors was daily adjusted to $1 \mathrm{~L}$ using deionized water to ensure that all membranes remained immersed in the medium.

During the microalgal biofilm growth, three replicate membrane samples were removed from the modules every 2 days for areal microalgal biomass determination using Eq. (1).

To understand the microalgal growth under normal conditions, Desmodesmus sp. was cultivated in suspension in a liquid culture at 6 different pH-values $(5,6,7,8,9$ and 10). The growth was monitored every day by measuring the optical density (OD) of microalgal broth using a spectrophotometer (DR-2800, Hach Lange, USA) at 680 $\mathrm{nm}$. The final biomass was determined using the procedure in 2.1 , and was expressed as $\mathrm{g} / \mathrm{L}$.

\subsection{Microalgae harvesting through biofilm detachment}

After 14 days of cultivation, the biofilms were harvested by a combination of 
hydrodynamic shear and $\mathrm{pH}$-tunable surface charge inversion. The modules with the attached biofilms were removed from the PBRs, transferred to the MMV system, and vibrated at a frequency of $1 \mathrm{~Hz}$ and amplitude of $5 \mathrm{~mm}$ in deionized water at different $\mathrm{pH}$-values $(5,6,7,8,9$ and 10). Before vibration, membranes were immersed in deionized water with different $\mathrm{pH}$-values for $30 \mathrm{~min}$. After $10 \mathrm{~min}$ vibration, the remaining microalgae and membranes were collected for analysis of the areal biomass density. The biofilm mass was determined by directly placing the membrane with the biofilm in the oven without vibration. The harvesting efficiency was calculated using Eq. (5):

$R_{h}(\%)=\frac{M_{b}-M_{r}}{M_{b}} \times 100$

where $R_{h}$ is the microalgal harvesting rate; $M_{b}$ the dry mass of biofilm biomass without vibration $(\mathrm{g}) ; M_{R}$ the dry mass of remind microalgae $(\mathrm{g})$.

\subsection{Characterization of membranes and microalgae}

The cross-sections and surfaces of membranes were observed using scanning electron microscopy (SEM, JEOL JFC-1300, Tokyo, Japan). The actual pattern height and inter-pattern distance were also determined using SEM, and the actual surface area of patterned membrane was theoretically calculated based on the actual pattern height and inter-pattern distance.

The contact angles of the membranes were determined using three probe liquids (MiliQ water, glycerol and diiodomethane), and were measured using a contact angle goniometer (Kruss, Drop Shape Analysis System, Germany) [50].

The membrane surface chemical composition was determined using attenuated total 
reflectance Fourier-transform infrared spectrometer (ATR-FTIR, Bruker Alpha, Germany) at a $4000-400 \mathrm{~cm}^{-1}$ scanning range.

The zeta potential ( $\mathrm{ZP})$ of the membrane surface at $6 \mathrm{pH}$-values was measured using an adjustable-gap measuring cell (SurPASS Electrokinetic Analyzer, AntonPaar), following the procedure described before [51].

Because the membrane surface topology may influence the ZP results, 2 different flat membranes (CL-FM and FM) were used. The surface properties of CL-FM and FM can represent the properties of crosslinked and un-crosslinked patterned membranes, respectively.

The mean diameter and morphology of Desmodesmus sp. cells were determined and observed using inverted microscopy operated through CellSens (IX83, Olympus Corporation, Japan).

The ZPs of Desmodesmus sp. at $6 \mathrm{pH}$-values were determined using a Nanobrook Omni Zeta Potential Analyzer (Brookhaven Corporate Park, Holtsville, USA), following the procedure described before [51].

For Desmodesmus sp. contact angle determination, a fresh mciroalgal broth was filtrated through an FM membrane using a high-throughput dead-end filtration system. The retained microalgae paste on the membrane surface was pressed to form a flat film. The resulting microalgal flat film was then dried under ambient temperature for $24 \mathrm{~h}$. The microalgal contact angle was also determined using contact angle goniometer and three probe liquids.

\subsection{CFD modeling}


Flow behavior near the surface of the different membranes was simulated using a commercial fluid dynamics software (Ansys 19.0, Ansys Inc., USA). The colored areas and path lines represent the distribution of velocity and flow direction. Wall shear on the membrane surface was expressed using single colored lines.

\subsection{Statistic analysis}

All experiments were carried out in triple, and the results were expressed as mean values \pm standard deviation. The significance of the results was analyzed using statistical product and service solutions (SPSS) 17.0 and analysis of variance (ANOVA) with least significant digit (LSD) analysis $(P<0.05)$.

\subsection{Interaction energy calculation}

The total interaction energy $\left(\Delta G^{T o t}, \mathrm{~mJ} / \mathrm{m}^{2}\right)$ between the membrane surface and microalgae cells in the medium, consisting of attractive Lifshitz-van der Waals (LW, $\Delta G^{L W}, \mathrm{~mJ} / \mathrm{m}^{2}$ ), electrostatic repulsive double layer (EL, $\Delta G^{E L}, \mathrm{~mJ} / \mathrm{m}^{2}$ ) and Lewis acid-base $\left(\mathrm{AB}, \Delta G^{A B}, \mathrm{~mJ} / \mathrm{m}^{2}\right)$ interactions [52], can be expressed as the XDLVO interaction energy per unit area between two infinite planar surfaces using Eqs. (6)-(9)

$$
\begin{aligned}
\Delta G^{T o t}= & \Delta G^{L W}+\Delta G^{E L}+\Delta G^{A B} \\
\Delta G_{l_{0}}^{L W}= & -2\left(\sqrt{\gamma_{M}^{L W}}-\sqrt{\gamma_{W}^{L W}}\right)\left(\sqrt{\gamma_{A}^{L W}}-\sqrt{\gamma_{W}^{L W}}\right) \\
\Delta G_{l_{0}}^{E L}= & \frac{\varepsilon \varepsilon_{0} \kappa}{2}\left(\zeta_{A}^{2}+\zeta_{M}^{2}\right)\left[1-\operatorname{coth}\left(\kappa l_{0}\right)+\frac{2 \zeta_{A} \zeta_{M}}{\zeta_{A}^{2}+\zeta_{M}^{2}} \operatorname{csch}\left(\kappa l_{0}\right)\right] \\
\Delta G_{l_{0}}^{A B}= & 2\left[\sqrt{\gamma_{W}^{+}}\left(\sqrt{\gamma_{A}^{-}}+\sqrt{\gamma_{M}^{-}}-\sqrt{\gamma_{W}^{-}}\right)+\sqrt{\gamma_{W}^{-}}\left(\sqrt{\gamma_{A}^{+}}+\sqrt{\gamma_{M}^{+}}-\sqrt{\gamma_{W}^{+}}\right)-\sqrt{\gamma_{A}^{-} \gamma_{M}^{+}}-\right. \\
& \left.\sqrt{\gamma_{A}^{+} \gamma_{M}^{-}}\right]
\end{aligned}
$$

where the subscripts $A, W$ and $M$ represent microalgae, water and membrane, 
respectively; $\gamma$ the surface tension parameter; $\gamma^{L W}, \gamma^{+}$and $\gamma^{-}$the LW component, electron-acceptor and electron-donor parameters, respectively; $l$ the microalgae-membrane distance between two infinite planar surfaces ( $l_{0}$ is the minimum microalgae-membrane distance); $\varepsilon(78.5)$ and $\varepsilon_{0}\left(8.854 \times 10^{-2} \mathrm{CV}^{-1} / \mathrm{m}\right)$ the dielectric constant of water and the dielectric permittivity of the vacuum, respectively [54]; $\kappa$ the inverse Debye length and can be calculated using Eq. (10) [53]; $\zeta_{A}$ and $\zeta_{M}$ the microalgae and membrane surface ZPs, respectively; $\Delta G_{l_{0}}^{L W}, \Delta G_{l_{0}}^{E L}$ and $\Delta G_{l_{0}}^{A B}$ are three interaction components at the minimum microalgae-membrane distance.

$\kappa=\sqrt{\frac{e^{2} \sum n_{i} z_{i}^{2}}{\varepsilon \varepsilon_{0} K T}}$

where $T$ is the absolute temperature; $e$ the electron charge; $n_{i}$ the number concentration of ion $i$ in microalgal broth; $z_{i}$ the valence of ion $i$; $K$ the Boltzmann's constant.

The total tension parameter $\left(\gamma^{T o t}\right)$, including $\mathrm{LW}\left(\gamma^{L W}\right)$ and $\mathrm{AB}\left(\gamma^{A B}\right)$ components [29], can be calculated using Eq. (11), which can also be calculated using the extended Young equation (EYE) by testing the contact angles using three probe liquids [55]. The EYE can be expressed as follows [56]:

$\gamma^{T o t}=\gamma^{L W}+\gamma^{A B}$

$(1+\cos \theta) \gamma_{L}^{T o t}=2\left(\sqrt{\gamma_{S}^{L W} \gamma_{L}^{L W}}+\sqrt{\gamma_{S}^{+} \gamma_{L}^{+}}\right)$

$\gamma^{A B}=2 \sqrt{\gamma^{-} \gamma^{+}}$

where the subscripts $S$ and $L$ represent the solid (i.e. membrane and microalgae) surface and the liquid (water), respectively.

Desmodesmus sp. is spherical according to the microscope observation, and the cell 
size ranges from 5.1-7.0 $\mu \mathrm{m}$. The Derjaguin approximation (DA) method was thus used to calculate the interaction energy components $\left(U_{s p h}^{L W}(l), U_{s p h}^{E L}(l)\right.$ and $\left.U_{s p h}^{A B}(l)\right)$ between a spherical surface (mciroalgal cell) and planar surface (membrane) [57]. The calculation can be expressed using Eqs. (14)-(16). $U_{s p h}^{L W}\left(l_{0}\right), U_{s p h}^{E L}\left(l_{0}\right)$ and $U_{s p h}^{A B}\left(l_{0}\right)$ represent three interaction energy components at the minimum microalgae-membrane distance for spherical and planar surfaces.

$$
\begin{aligned}
& U_{s p h}^{L W}(l)=2 \pi \Delta G_{l_{0}}^{L W} \frac{l_{0}^{2} a_{A}}{l} \\
& U_{s p h}^{E L}(l)=\pi \varepsilon \varepsilon_{0} a_{A}\left[2 \zeta_{A} \zeta_{M} \ln \left(\frac{1+e^{-\kappa l}}{1-e^{-\kappa l}}\right)+\left(\zeta_{A}^{2}+\zeta_{M}^{2}\right) \ln \left(1-e^{-2 \kappa l}\right)\right] \\
& U_{s p h}^{A B}(l)=2 \pi a_{A} \lambda \Delta G_{l_{0}}^{A B} \exp \left(\frac{l_{0}-l}{\lambda}\right)
\end{aligned}
$$

where $a_{A}$ is the mciroalgal cell radius and $\lambda(0.6 \mathrm{~nm})$ the decay length of $\mathrm{AB}$ interaction in aqueous solution [16].

\section{Results and discussion}

\subsection{Characterization of membranes and microalgae}

PVDF membranes were crosslinked using a one-pot method to simultaneously realize dehydrofluorination and PEI-crosslinking (Fig. 1). The successful introduction of PEI on the PVDF membrane surface was verified using FTIR (Fig. 3). The spectrum of PEI-crosslinked PVDF membrane shows a broad absorption peak at $\sim 3298 \mathrm{~cm}^{-1}$, which can be attributed to the N-H stretch of the amine group [58]. A noticeable characteristic peak at $\sim 1544 \mathrm{~cm}^{-1}$ is ascribed to the $\mathrm{N}-\mathrm{H}$ bending in PEI [59]. In addition, a small absorption peak observed at $\sim 1335 \mathrm{~cm}^{-1}$ is attributed to the C-N stretch in PEI [60]. 


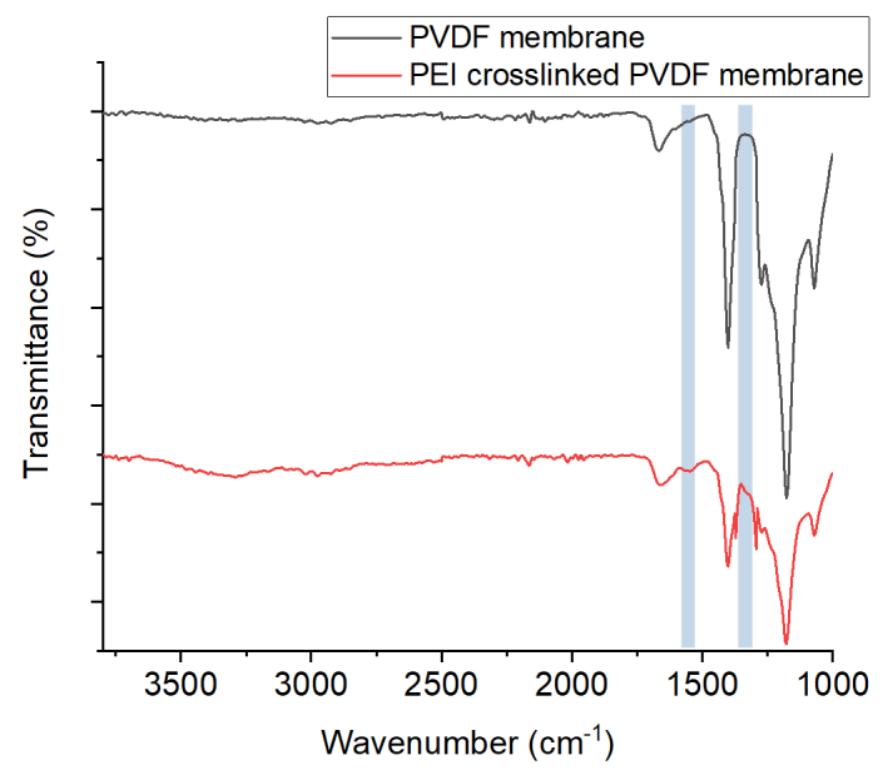

Fig. 3 ATR-FTIR spectra of the PVDF and PEI-crosslinked PVDF membranes.

The surface and cross-sectional morphologies of the flat and patterned membranes are shown in Fig. 4. All cross-sections show the expected asymmetric structure with finger-like macrovoids. For patterned membranes, the patterns on the membrane surface do not completely reflect the original shapes of the casting knives, as the patterns shrink anisotropically during the solidification process [61].

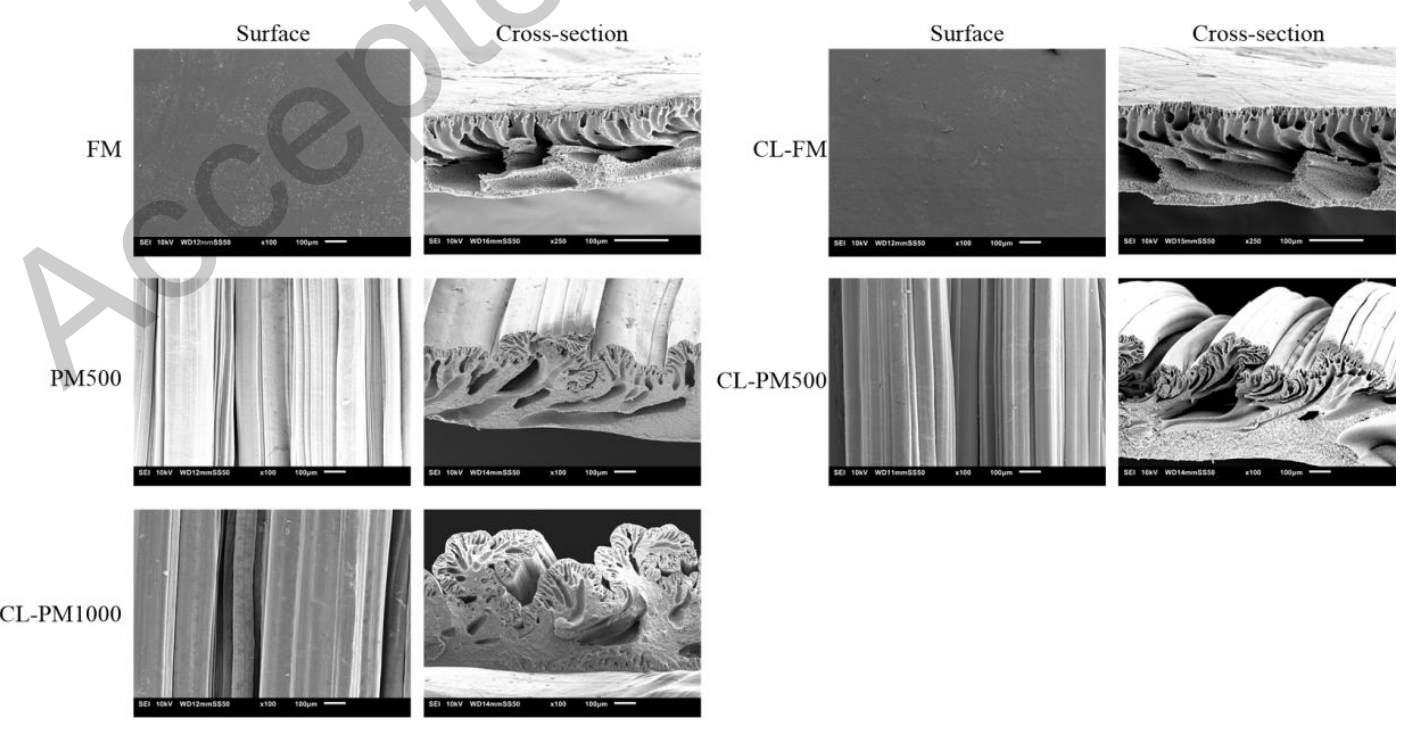

Fig. 4 Surface and cross-sectional images of the flat and patterned membranes.

The membrane surface hydrophilicity was significantly increased after PEI crosslinking (Table 1) (i.e. the water contact angle of CL-FM was lower than that of 
FM membrane). The ZPs of FM membrane were always negative at any $\mathrm{pH}$, while those of CL-FM membrane were positive at $\mathrm{pH} \leq 8$ and negative at $\mathrm{pH} \geq 9$, proving the pH-responsive, charge-switchable properties of these crosslinked membranes, as also found elsewhere [37].

Table 1 Contact angle and zeta potential data of membranes and Desmodesmus sp..

\begin{tabular}{|c|c|c|c|c|c|c|c|c|c|}
\hline \multirow[t]{2}{*}{ Sample } & \multicolumn{3}{|c|}{ Contact angle $\left({ }^{\circ}\right)$} & \multicolumn{6}{|c|}{ Zeta potential $(\mathrm{mV})$} \\
\hline & $\theta_{\text {wat }}^{a}$ & $\theta_{g l y}{ }^{a}$ & $\theta_{d i i}{ }^{a}$ & pH 5 & $\mathrm{pH} 6$ & $\mathrm{pH} 7$ & pH 8 & & $\mathrm{pH} 10$ \\
\hline FM & $84.8 \pm 0.4$ & $87.4 \pm 0.7$ & $47.2 \pm 0.8$ & -44.1 & -47.4 & & 2 & -56.2 & -59.0 \\
\hline CL-FM & $66.7 \pm 2.6$ & $70.8 \pm 0.7$ & $27.5 \pm 1.2$ & 12.4 & & & 6.3 & -0.3 & -13.3 \\
\hline Algae & $83.2 \pm 2.5$ & $64.7 \pm 1.1$ & $43.8 \pm 1.8$ & 16 & -17 & -18.0 & -18.0 & -18.5 & -18.8 \\
\hline
\end{tabular}

${ }^{\mathrm{a}} \theta_{\text {wat }}, \theta_{g l y}, \theta_{\text {dii }}$ are the contact angles determined using Milli-Q water, glycerol and diiodomethane, respectively.

Interfacial Gibbs free energies were calculated based on the surface tension data (Table 2). The contribution of the EL free energy is normally a magnitude lower than that of $L W$ and $A B$ free energies and can be considered as negligible $[54,62]$. The total interfacial Gibbs free energy $\left(\Delta G_{l_{0}}^{\text {Tot }}\right)$ was therefore calculated by the sum of $\Delta G_{l_{0}}^{L W}$ and $\Delta G_{l_{0}}^{A B}$. A negative value of $\Delta G_{l_{0}}^{T o t}$ represents an attractive interaction, on the contrary a repulsive interaction [55]. In addition, a higher absolute value of $\Delta G_{l_{0}}^{T o t}$ means a higher attractive strength between two surface [55]. From Table 2, negative values of $\Delta G_{l_{0}}^{T o t}$ indicate an attractive interaction between membrane and microalgal cells as well as microalgal cells themselves. The most negative value is found 
between microalgal cells (-67.7), indicating that microalgal cells tend to aggregate more and form biofilm. The $\Delta G_{l_{0}}^{\text {Tot }}$ values of FM and CL-FM are very similar, indicating a similar microalgal attachment at the minimum microalgae-membrane distance. The surface properties of CL-FM can be considered as approximately the same as for the crosslinked patterned membranes.

Table 2 Surface tensions and interfacial Gibbs free energies at a minimum microalgae-membrane distance.

\begin{tabular}{|c|c|c|c|c|c|c|c|c|}
\hline \multirow[t]{2}{*}{ Sample } & \multicolumn{5}{|c|}{ Surface tension $\left(\mathrm{mJ} / \mathrm{m}^{2}\right)$} & \multicolumn{3}{|c|}{ Gibbs free energy $\left(\mathrm{mJ} / \mathrm{m}^{2}\right)$} \\
\hline & $\gamma^{L W}$ & $\gamma^{-}$ & $\gamma^{+}$ & $\gamma^{A B}$ & $\gamma^{T O L}$ & & $\Delta G_{l_{0}}^{A B}$ & $\Delta G_{l_{0}}^{T o}$ \\
\hline FM & 35.8 & 11.6 & 1.2 & 7.5 & 43.3 & & -47.8 & -51.5 \\
\hline CL-FM & 45.2 & 21.2 & 0.6 & 7 & & -6.0 & -44.0 & -50.0 \\
\hline Algae & 37.6 & 0.04 & 4.8 & 0.9 & 38.5 & -4.3 & -63.4 & -67.7 \\
\hline
\end{tabular}

\subsection{Initial attachment and detachment of microalgae on the membrane surface}

A thin layer of microalgae was attached to the membranes using dead-end filtration. The total amount of microalgae deposited on each membrane surface corresponded to $54.2 \mathrm{~g} / \mathrm{m}^{2}$. The membranes were subsequently potted into a MMV module and the amount of biomass remaining on the membrane surface was quantified (i.e. areal biomass for microalgal initial attachment, Fig. 5a). The percentage of the biomass that was deposited on the filter and that was detached after vibration at $\mathrm{pH} 7$ was calculated as the initial detachment (Fig. 5b). The initial detachment reflects the initial attachment strength, i.e. a higher initial detachment means a higher initial attachment strength. For FM and PM500 membranes, no significant difference $(P>0.05)$ was 
noted between pH-levels in initial microalgal attachment and detachment at all $\mathrm{pH}$-values, indicating that $\mathrm{pH}$ did not affect the microalgal attachment on the un-crosslinked PVDF membranes. However, significant differences $(P<0.05)$ were observed between different pH-levels for the CL-FM, CL-PM500 and CL-PM1000 membranes, showing that with increasing $\mathrm{pH}$, the microalgal initial attachment decreased, while initial detachment increased. There was no significant difference for crosslinked PVDF membranes at $\mathrm{pH}$ 5-7. When $\mathrm{pH}$ reached 8, a sharp decrease for crosslinked membranes was observed. Crosslinked PVDF membranes showed higher initial microalgal attachment at $\mathrm{pH} \leq 7$ than the corresponding un-crosslinked PVDF membranes, while lower at $\mathrm{pH} \geq 9$ (Table 3 ). This phenomenon might be explained by electrostatic attraction and repulsion [37]. Uncombined amine groups on the crosslinked PVDF membrane surface generate a $\mathrm{pH}$-responsive surface charge on the membrane surface, giving membranes a negatively charged surface at $\mathrm{pH} \geq 9$, and a positively charged at $\mathrm{pH} \leq 8$ (Table 1 ). The surface charges of Desmodesmus sp. cells are negative at the entire $\mathrm{pH}$ range from 5 to 10 (Table 1). Microalgal cells can therefore be attracted to the crosslinked PVDF membrane surface at $\mathrm{pH} \leq 8$, while being repelled at $\mathrm{pH} \geq 9$.

PEI-modified surfaces have been commonly used for cell adhesion (e.g. in tissue culture and on the anode of microbial fuel cells). A PEI modified poly( $\varepsilon$-caprolactone) scaffold showed a higher hydrophilicity than an un-modified one, and could increase fibroblast adhesion and proliferation [63]. Yeast cells could also be strongly attracted by PEI modified jute fabric [64]. In addition, PEI modified carbon felt could attract 
and entrap more Saccharomyces cerevisiae cells [65]. However, current research is the first to integrate PEI into a membrane for microalgal biofilm attachment and harvesting.

Table 3 Microalgal initial attachment trends at different pH-values

\begin{tabular}{ll} 
pH-value & Trend \\
\hline$\leq 7$ & CL-PM1000>CL-PM500>PM500>CL-FM>FM \\
8 & CL-PM1000>CL-PM500>PM500>FM>CL-FM \\
$\geq 9$ & PM500>FM>CL-PM1000>CL-PM500>CL-FM
\end{tabular}

In addition to surface charge, the surface patterns also had a significant effect on the initial attachment. Patterned membranes showed a higher microalgal initial attachment than the corresponding flat membranes at $\mathrm{pH}$ 5-10 (Fig. 5a), confirming that the patterned surface can immobilize more microalgal cells on its extended membrane surface. The areal microalgal biomass was calculated based on the apparent surface area. The theoretical actual surface areas of PM-500 and PM-1000 membranes were almost 3 and 4 times as high as for the flat membrane. The extended effective membrane area obviously offers more place for microalgal attachment. In addition, the unique dynamic flow behavior near the membrane surface offers a relatively stagnant zone in the valleys with lower shear and flow velocity, allowing more microalgal cells to deposit [40]. CL-PM1000 membrane showed higher initial microalgal attachment than CL-PM500 membrane, indicating that patterns with increased height can immobilize more microalgal cells. A similar situation was also found in previous studies where a patterned PSf membrane with larger patterns could 
trap more microalgal cells in the valleys [40], and a patterned PVDF membrane also showed the same trend [66]. The initial attachment time of S. obliquus on a patterned polydimethylsiloxane (PDMS) membrane was significantly shortened from $135 \mathrm{~min}$ to 50 min, indicating the benefit of surface patterning [14]. The possible reason is that at low Re numbers, the possibility for microalgal cells deposition increases when the volume of a valley region is large [67].

Moreover, an interesting phenomenon was that when only involving surface charge or surface pattern on the PVDF membrane (i.e. comparing FM membrane with CL-FM or PM-500 membranes) at $\mathrm{pH} \leq 7$, only small increases of microalgal initial attachment were found. However, when combing surface charge with surface pattern (i.e. comparing FM membrane with CL-PM500 or CL-PM1000 membranes), a very large improvement was found, revealing a synergy between electrostatic attraction and surface patterns to enhance microalgal attachment.

Another interesting phenomenon was that the trends of microalgal initial attachment and attachment strength at $\mathrm{pH}=8$ did not follow the trends at $\mathrm{pH} \leq 7$ nor $\mathrm{pH} \geq 9$ (Table 3 ). This may be explained by the dominance of surface charge or surface pattern. Microalgal attachment was mainly dominated by the synergy between electrostatic attraction and surface pattern at $\mathrm{pH} \leq 7$, and mainly electrostatic repulsion at $\mathrm{pH} \geq 9$. Microalgal initial attachment on the CL-FM membrane was lower than on the FM membrane at $\mathrm{pH}=8$ even with electrostatic attraction. The possible reason is that the electrostatic attraction effect was not strong enough to resist shear generated by vibration, and CL-FM was more hydrophilic than FM membrane (i.e. higher 
fouling resistance [68]) (Table 1).

A pH of 7 was thus selected for microalgal initial attachment, considering that there was no significant difference $(P>0.05)$ between $\mathrm{pH} 5,6$ or 7 .
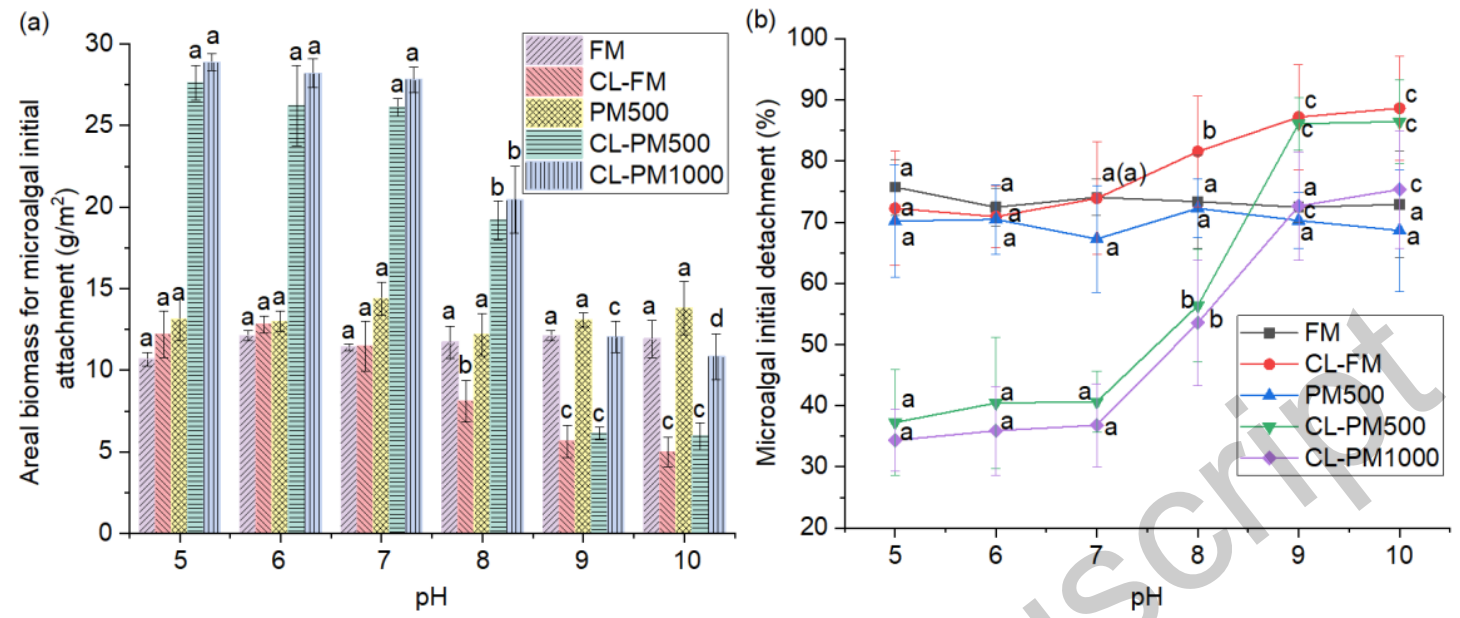

Fig. 5 Microalgal initial (a) attachment and (b) detachment.

Note: different lower-case letters per membrane at different $\mathrm{pH}$ indicate results that are significantly $(P<0.05)$ different.

\subsection{Microalgal biofilm growth analysis}

After initial attachment at $\mathrm{pH} 7$, the microalgal biofilm growth at different $\mathrm{pH}$ levels on the flat and patterned membranes was monitored under static conditions for 14 days, and the daily biomass was monitored by measuring the microalgal dry weight on the membranes every 2 days. For comparison, growth of the same microalgae as a suspension in liquid culture medium was also evaluated at different $\mathrm{pH}$ levels, and the microalgal growth was monitored by measuring the OD of the broth every day. The growth of the microalgal biofilm is depicted in Figs. 6a-6i, which was calculated based on the apparent membrane surface area (i.e. not including the separate areas that from the parts of the valleys that are perpendicular to the 
membrane surface). For systems operated at different $\mathrm{pH}$-values, the microalgal biofilm growth curves on CL-PM500 and CL-PM1000 membranes were situated above those of the other membranes, indicating a higher areal biomass (Figs. 6a-6g). This could be explained by the higher initial microalgal attachment onto CL-PM500 and CL-PM1000 membranes. Not just for CL-PM500 and CL-PM1000 membranes, the daily areal microalgal biomass increased along with the initial attachment throughout the whole cultivation time for all membranes. Initial inoculation (i.e. initial attachment) size has a significant effect on microalgal growth and final biomass [69]. On one hand, a high initial microalgal is beneficial for microalgal survival, especially in the presence of other microorganisms $[69,70]$. On the other hand, biofilm proliferation is mostly driven by the areal photon absorption. Therefore, a higher initial attachment may give a higher substrate coverage, resulting in a higher areal photon absorption [71]. Similar results were found in previous studies where biofilms with higher initial inoculation size showed higher final microalgal biomass $[71,72]$.

$\mathrm{pH}$ significantly affects microalgal biofilm growth by adjusting the physiological reactions in the microalgae and their nutritional requirements [73]. The optimal $\mathrm{pH}$ is thus always species-dependent [74]. pH-responsive membranes may thus present different biofilm growth performances at different $\mathrm{pH}$-values. Desmodesmus sp. biofilm growth was therefore investigated on different membranes at different $\mathrm{pH}$-values. The biofilms almost stopped proliferation at $\mathrm{pH}<7$ (Figs. $6 \mathrm{a}$ and $6 \mathrm{~b}$ ), while reaching the highest growth rate at $\mathrm{pH}=7$ (Fig. 6c). However, with further increasing 
$\mathrm{pH}$, the growth rate decreased (Figs. 6d-6f). The highest final biofilm biomass was obtained on the CL-PM1000 membrane $\left(97.9 \mathrm{~g} / \mathrm{m}^{2}\right)$ at $\mathrm{pH}=7$ (Fig. $6 \mathrm{~g}$ ), and the biofilm biomasses on crosslinked patterned membranes were significantly higher than those on other membranes, in line with the results in 3.2. The biofilm growths at different $\mathrm{pH}$-values were similar to the results in broth cultivation (Fig. 6h and 6i) where a $\mathrm{pH}$ of 7 gave the best microalgal growth followed in order by a $\mathrm{pH}$ of $8,9,10$, 6 and 5. Microalgae also almost stopped growing at $\mathrm{pH} \leq 6$. Even though the growth curves at pH 9 and 10 almost overlap, the final dry biomass at pH $9(0.72 \mathrm{~g} / \mathrm{L})$ was still a bit higher than that at $\mathrm{pH} 10(0.69 \mathrm{~g} / \mathrm{L})(P<0.05)($ Fig. 6i). The results suggested that pH 7 was ideal for Desmodesmus sp. biofilm growth, and Desmodesmus sp. can survive at high $\mathrm{pH}$, while a low $\mathrm{pH}$ may restrict the growth.

A flat glass and plastic surface has been used for S. obliquus biofilm formation, showing final biofilm biomass of 22 and $52 \mathrm{~g} / \mathrm{m}^{2}$, respectively [75, 76]. In current study, by introducing surface patterns and $\mathrm{pH}$-tunable charge on the membrane surface, the biofilm biomass thus reached up to $97.9 \mathrm{~g} / \mathrm{m}^{2}$, indicating a strong advantage of the synergy between surface pattern and charge. A patterned PDMS membrane has also been used in a hydrodynamic system for S. obliquus biofilm formation, achieving the highest final biofilm biomass of $165 \mathrm{~g} / \mathrm{m}^{2}$ [14]. The higher biomass in this study may be explained by the advantages of hydrodynamic effects and horizontal position. The hydrodynamic conditions optimized the nutrient provisions and removed generated metabolic waste from the microalgal film, therefore promoting further biofilm growth [77]. Besides, horizontal cultivation may 
prevent biofilm falling from the substrate due to gravity. The biofilms in the current approach were cultivated vertically under static conditions. Further optimization may expect to achieve an even higher biofilm concentration. Another possible reason is the different microalgal species used here, which also impacts strongly the final biofilm biomass.

It is known that PEI is potentially cytotoxic [78] and can kill cells so as to prevent bacterial growth when the polycation penetrates the cells [79-81]. However, it was reported that the cytotoxicity of PEI modified surfaces can be well controlled by decreasing PEI concentration [23, 82]. In addition, it was also reported that PEI may possess a less pronounced cytotoxic effect on algae, due to the extra protection of the cell wall $[79,81,83]$. The crosslinked PEI quantity on the PVDF membrane surface was far less than the reported cell lethal dosage (the median inhibitory concentration of 25000 Da branched PEI for A431 cells was 16w\% [84]), and no significant microalgal apoptosis was observed in current study, proving the safety of the PEI-crosslinked membranes. 

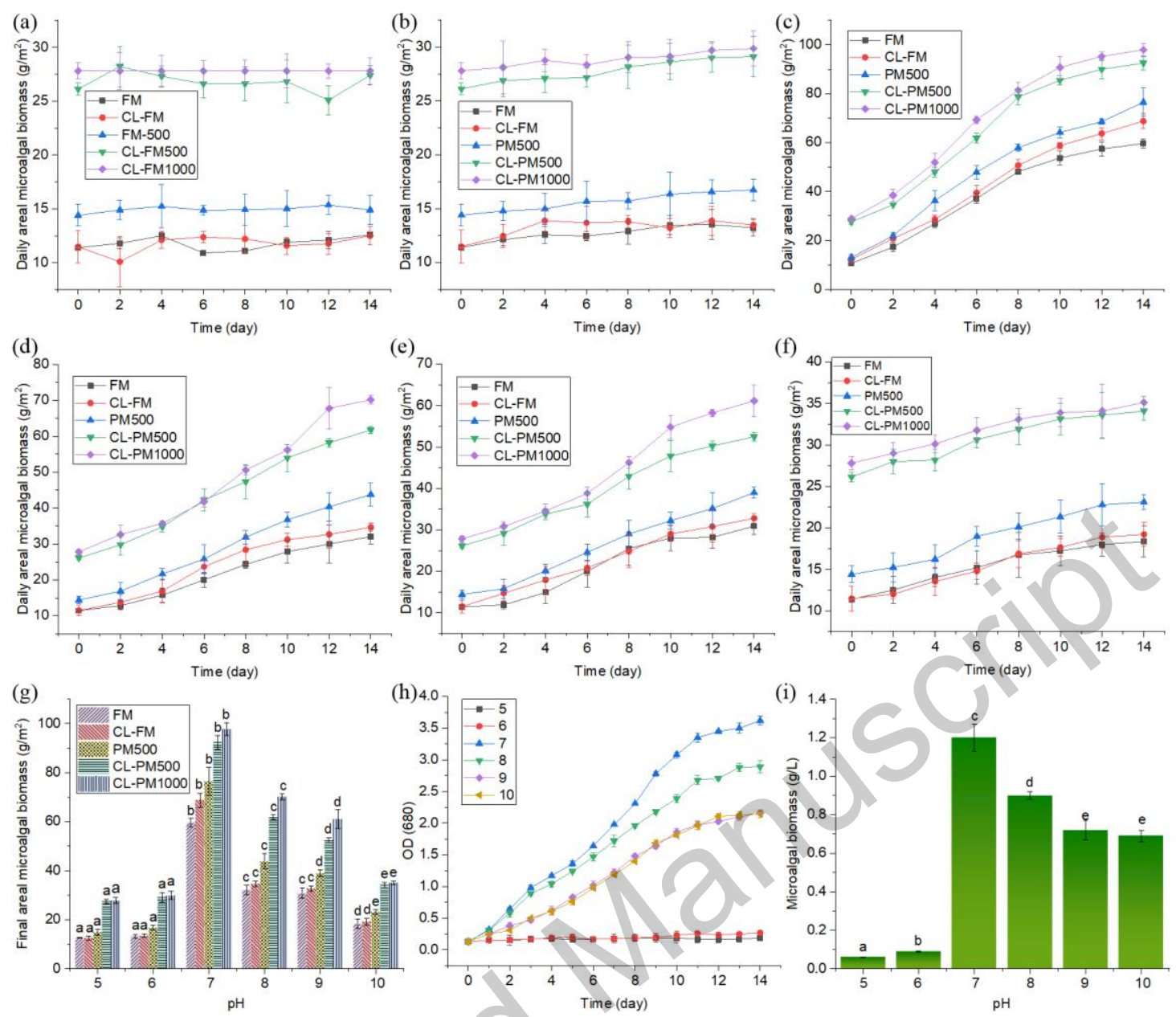

Fig. 6 (a-f) Evolutionary microalgal biofilm growths on membrane substrates at different pH-values (a 5; b 6; c 7; d 8; e 9; f 10), (g) final microalgal biofilm biomass on membrane substrates at different $\mathrm{pH}$-values after 14 days cultivation, (h) evolution of microalgal growth as a suspension in liquid culture medium (i.e. without membrane substrate) at different $\mathrm{pH}$-values, and (i) final microalgal biomass after 14 days liquid medium cultivation without substrate.

Note: (g) different lower-case letters per membrane indicate results that are significantly $(P<0.05)$ different; (i) different lower-case letters per pH-value indicate results that are significantly $(P<0.05)$ different.

3.4 Microalgal biofilm harvesting by $\mathrm{pH}$-induced detachment 
After 14 days of cultivation at $\mathrm{pH}=7$, microalgal biofilms were harvested by detachment using the MMV system at different $\mathrm{pH}$ levels. A higher detachment means higher harvesting efficiency. A similar trend was also found when harvesting biofilms (Fig. 7). The harvesting efficiency of crosslinked membranes increased with increasing $\mathrm{pH}$, while $\mathrm{pH}$ did not significantly influence that of un-crosslinked membranes. Besides, flat membranes showed a higher harvesting efficiency than patterned membranes. At $\mathrm{pH}>9$, the harvesting efficiencies of crosslinked membranes were higher than $90 \%$, suggesting that microalgal biofilms on PEI-crosslinked PVDF membranes can be best harvested by adjusting $\mathrm{pH}$ above 9. However, a higher detachment (i.e. harvesting efficiency) was found compared with the initial detachment. A possible reason is that when the biofilm became thick, the operated shear rate $\left(34.5 \mathrm{~s}^{-1}\right)$ on the biofilm surface can only remove microalgae-microalgae combined consortia, and only the microalgae which closely attached on the membrane surface remain, therefore giving a higher detachment rate. The higher detachment rate at high $\mathrm{pH}$ can be ascribed to electrostatic repulsion. Because of the electrostatic repulsion effect, crosslinked membranes at $\mathrm{pH}>9$ gave an even higher detachment rate. The biofilm can not be completely removed from the membrane surface and this reduces the yields somehow. However, the remaining microalgal cells can be used as a seed to produce a new biofilm [14]. 


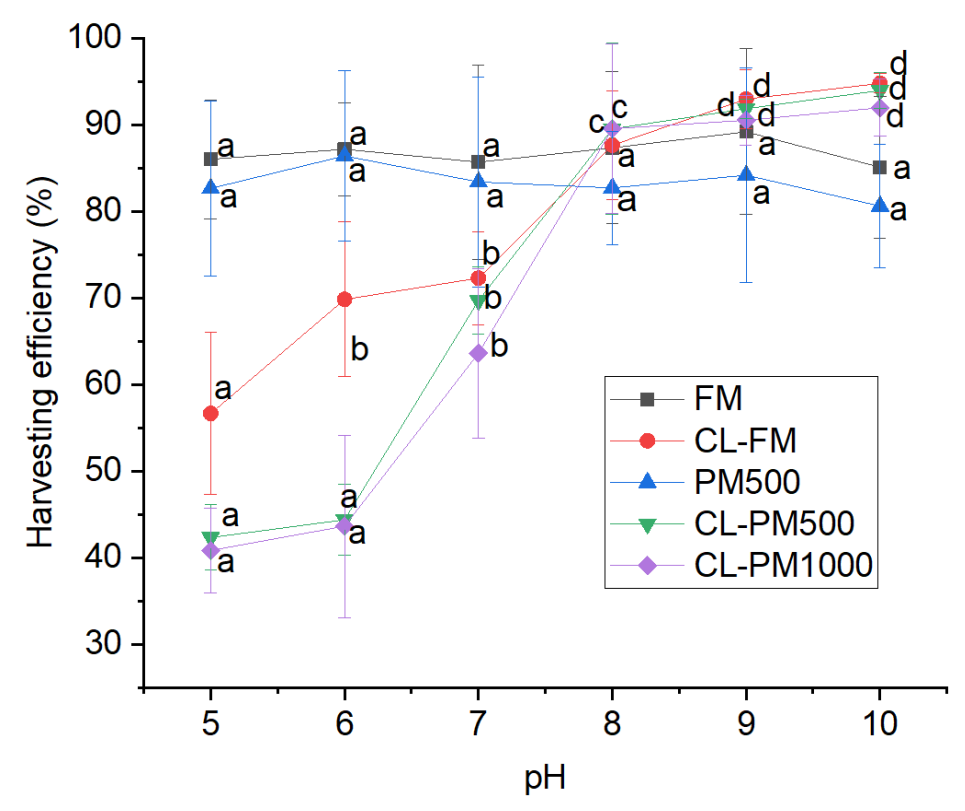

Fig. 7 Microalgal biofilm harvesting efficiencies at different pH-values after 14 days cultivation at $\mathrm{pH}=7$.

Note: different lower-case letters per membrane indicate results that are significantly $(P<0.05)$ different.

\subsection{Flow behavior near the membrane surfaces and interaction energy analysis}

Fig. 8 shows a velocity path line profile and wall shear contour line inside the flow channel using CFD modeling under a Re number of 273. The red color represents a higher velocity and wall shear, and the blue color a lower. As expected, the velocity and wall shear in the apex region are higher than those in the valley region (Figs. 8a, $8 \mathrm{~b}, 8 \mathrm{~d}$ and $8 \mathrm{e}$ ), confirming the results in 3.2: due to the lower flow velocity and wall shear, more microalgal cells could deposit in the valley region. Besides, the wall shear on some parts of the patterned membrane is too low to show (Fig. 8d and 8e), while the velocity and wall shear profiles of a flat membrane show a linear path line, indicating a constant flow behavior near the membrane surface. This can also explain the results in 3.2 and 3.4 on why flat membranes always gave a higher microalgal 
detachment rate not considering surface charge effect. The results are in line with previous studies in which the velocity profiles of patterned PSf membranes also showed a high-velocity up flow on apex region and a low-velocity down flow in valley region, and the wall shear profiles showed discontinuous contour line on the membrane surface $[40,85]$.

The profiles of total interaction energies between microalgal cells and two flat membranes (FM and CL-FM membranes) at different pH-values are shown in Fig. 9. A positive value represents a repulsive energy, on the contrary an attractive energy. The total interaction energy profile indicates that microalgal adhesion on the membrane surface must overcome an energy barrier [53]. Therefore, a higher repulsive energy barrier represents that only a small part of microalgal cells can eventually adhere on the membrane surface even though the interaction energy at minimum microalgae-membrane distance is negative. For FM membrane, similar trends are found at all $\mathrm{pH}$-values (Fig. 9a), with decreasing the distance between microalgae and membrane surface, the repulsive energy increases, indicating s less microalgae attached membrane surface. With increasing $\mathrm{pH}$, the repulsive energy increases. However, the interaction energies for FM membrane at different $\mathrm{pH}$-values are highly close, which may explain why the microalgal attachment and detachment rates at different $\mathrm{pH}$-values did not show significant difference in line with the results in 3.2 and 3.4. For CL-FM membrane, $\mathrm{pH}$ significantly influences the interaction energy (Fig. 9b). When $\mathrm{pH} \geq 9$, the energy barrier still exists, while disappears when $\mathrm{pH} \leq 8$. This may explain why CL-FM membrane showed higher microalgal 
attachment rate at $\mathrm{pH} \leq 8$. However, the interaction energy at $\mathrm{pH}=8$ is still higher than that at $\mathrm{pH}$ from 5 to 7 , indicating a weaker attractive energy. When introducing vibration, the attractive energy at $\mathrm{pH}=8$ may not resist shear generated by vibration, resulting in a significant decrease of microalgal attachment in accordance with the results in 3.2. Analogously, the interaction energy property of CL-FM membrane can approximately represent that of CL-P500 and CL-P1000 membranes.

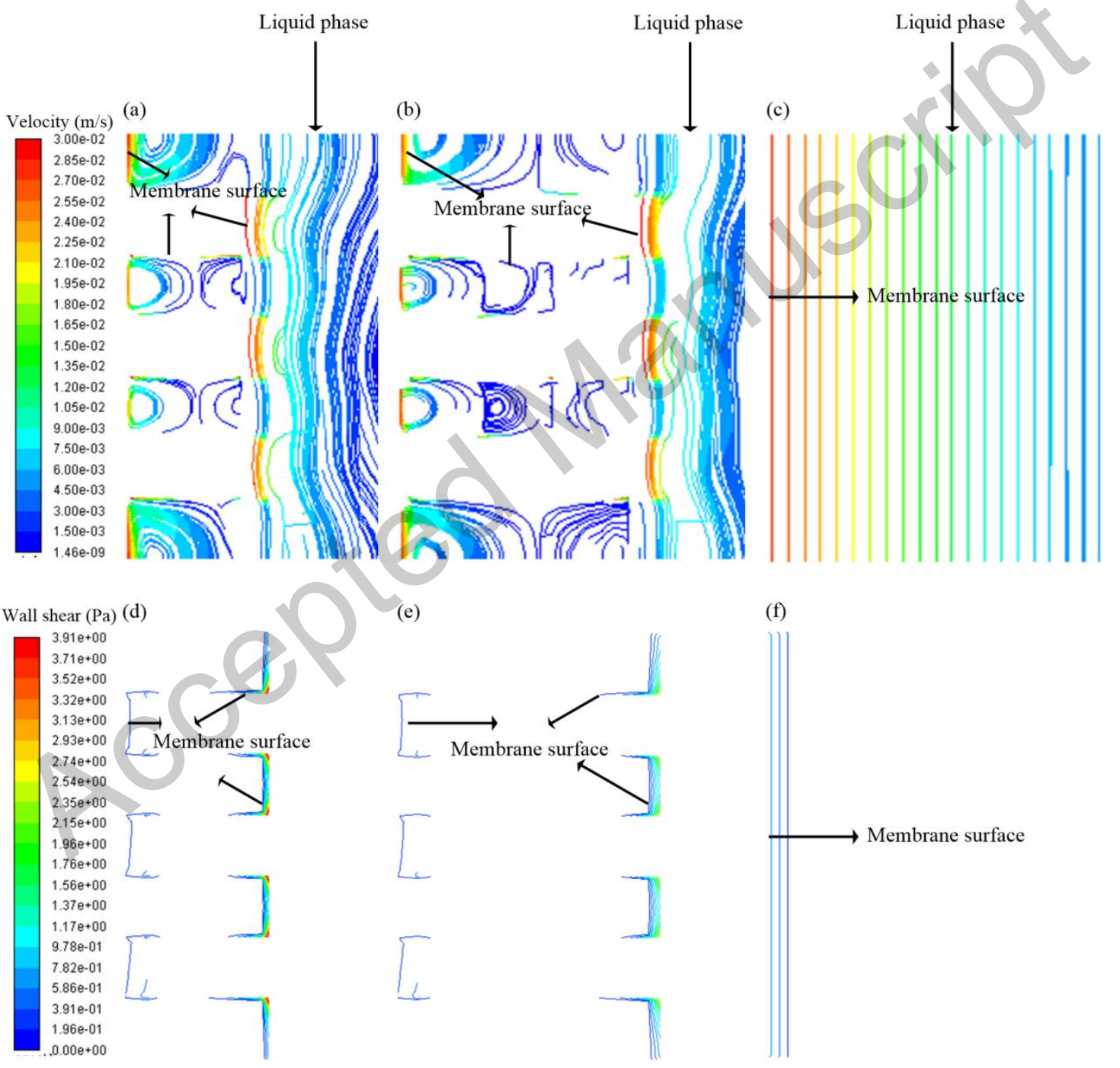

Fig. 8 (a-c) Velocity, streamline and (d-f) wall shear contour line profiles simulated by CFD modeling for the patterned membrane with (a and d) pattern height of $500 \mu \mathrm{m}$ and (b and e) $1000 \mu \mathrm{m}$, and (c and f ) flat membrane under 
$\mathrm{Re}=273$. The graphs showed the cross-sections of membranes.
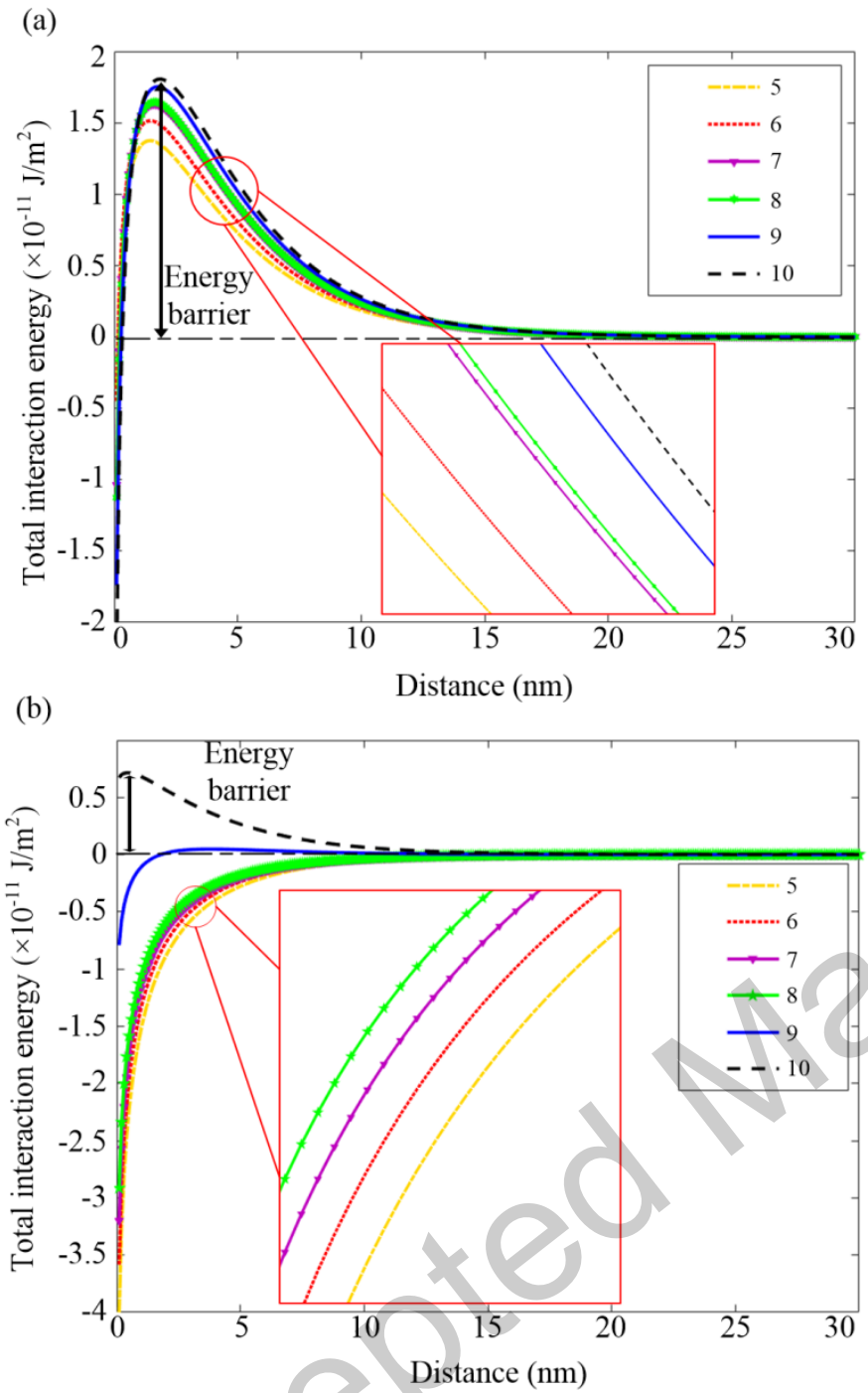

Fig. 9 Fig. 9 Profiles of total interaction free energies for membrane-microalgal cells combination as a function of the distance between microalgae and membrane surface at different $\mathrm{pH}$-values (the average microalgal cells radius is 6.1 $\mu \mathrm{m})$. (a) for FM membrane; (b) for CL-FM membrane.

\section{Conclusions}

PEI-crosslinked, patterned membranes were used as a substrate to grow biofilms of the microalgae Desmodesmus sp.. Attachment of cells onto the membrane was optimal at $\mathrm{pH} \leq 7$. Biofilm biomass accumulation was optimal at $\mathrm{pH}=7$, while the most 
efficient microalgal harvesting was found at $\mathrm{pH} \geq 9$. Corrugated membranes with increased pattern heights gave a higher microalgal initial attachment. The synergy between the $\mathrm{pH}$-tunable surface charge and surface patterns significantly improved the microalgal biofilm formation. Moreover, the $\mathrm{pH}$-responsiveness of the crosslinked membranes facilitated microalgal harvesting by $\mathrm{pH}$-induced detachment.

The mechanism of enhancing microalgal biofilm formation and realizing easy harvesting for crosslinked, patterned membranes was unraveled based on interaction energy and CFD modeling. Interaction energies at different $\mathrm{pH}$-values calculated using the improved XDLVO theory, showed a higher repulsive energy at $\mathrm{pH} \geq 9$ and attractive energy at $\mathrm{pH} \leq 8$, thereby proving the $\mathrm{pH}$-responsive microalgae attraction/repulsion switchable property. CFD modeling showed a lower velocity and shear in the valleys of the patterns, indicating that the patterns in the flow channel can offer a relatively stagnant area for microalgae deposition. The membrane with higher pattern heights gave a larger low-shear area space. The PEI-crosslinked PVDF membranes thus clearly have potential to combine high-density microalgal biofilm cultivation with low-cost harvesting.

\section{Acknowledgements}

$\mathrm{KU}$ Leuven is acknowledged for $\mathrm{C} 1$ funding. Zhenyu Zhao acknowledges the China Scholarship Council for financial support.

\section{Reference}

[1] Z. Yin, L. Zhu, S. Li, T. Hu, R. Chu, F. Mo, D. Hu, C. Liu, B. Li, A comprehensive review on cultivation and harvesting of microalgae for biodiesel production: 
environmental pollution control and future directions, Bioresource Technology (2020) 122804.

[2] Z. Zhao, S. Cuellar Bermudez, A. Ilyas, K. Muylaert, I.F.J. Vankelecom, Optimization of negatively charged polysulfone membranes for concentration and purification of extracellular polysaccharides from Arthrospira platensis using the response surface methodology, Separation and Purification Technology 252 (2020) 117385.

[3] Z. Zhao, Y. Li, K. Muylaert, I.F.J. Vankelecom, Synergy between membrane filtration and flocculation for harvesting microalgae, Separation and Purification Technology 240 (2020) 116603.

[4] A. Verfaillie, J. Blockx, R. Praveenkumar, W. Thielemans, K. Muylaert, Harvesting of marine microalgae using cationic cellulose nanocrystals, Carbohydrate Polymers 240 (2020) 116165.

[5] Y. Zheng, Y. Huang, A. Xia, F. Qian, C. Wei, A rapid inoculation method for microalgae biofilm cultivation based on microalgae-microalgae co-flocculation and zeta-potential adjustment, Bioresource Technology 278 (2019) 272-278.

[6] R. Sekar, V.P. Venugopalan, K. Nandakumar, K.V.K. Nair, V.N.R. Rao, Early stages of biofilm succession in a lentic freshwater environment, Hydrobiologia 512 (2004) 97-108.

[7] C.D. Nadell, K. Drescher, N.S. Wingreen, B.L. Bassler, Extracellular matrix structure governs invasion resistance in bacterial biofilms, The ISME Journal 9 (2015) 1700-1709. 
[8] Q. Su, M.D. Gilchrist, Demolding forces for micron-sized features during micro-injection molding, Polymer Engineering \& Science 56 (2016) 810-816.

[9] J. Wang, J. Liu, T. Liu, The difference in effective light penetration may explain the superiority in photosynthetic efficiency of attached cultivation over the conventional open pond for microalgae, Biotechnology for Biofuels 8 (2015) 49 .

[10] J. Liu, W. Vyverman, Differences in nutrient uptake capacity of the benthic filamentous algae Cladophora sp., Klebsormidium sp. and Pseudanabaena sp. under varying N/P conditions, Bioresource Technology 179 (2015) 234-242.

[11] F. Gao, Z.-H. Yang, C. Li, G.-M. Zeng, D.-H. Ma, L. Zhou, A novel algal biofilm membrane photobioreactor for attached microalgae growth and nutrients removal from secondary effluent, Bioresource Technology 179 (2015) 8-12.

[12] W. Cao, Y. Zhang, Removal of nitrogen (N) from hypereutrophic waters by ecological floating beds (EFBs) with various substrates, Ecological Engineering 62 (2014) 148-152.

[13] J. Liu, Y. Wu, C. Wu, K. Muylaert, W. Vyverman, H.-Q. Yu, R. Muñoz, B. Rittmann, Advanced nutrient removal from surface water by a consortium of attached microalgae and bacteria: A review, Bioresource Technology 241 (2017) 1127-1137.

[14] Y. Huang, Y. Zheng, J. Li, Q. Liao, Q. Fu, A. Xia, J. Fu, Y. Sun, Enhancing microalgae biofilm formation and growth by fabricating microgrooves onto the substrate surface, Bioresour Technol 261 (2018) 36-43.

[15] J. Kim, H.-D. Park, S. Chung, Microfluidic Approaches to Bacterial Biofilm Formation, Molecules 17 (2012) 9818-9834. 
[16] Y. Shen, X. Xu, Y. Zhao, X. Lin, Influence of algae species, substrata and culture conditions on attached microalgal culture, Bioprocess and Biosystems Engineering 37 (2014) 441-450.

[17] M. Hultberg, H. Asp, S. Marttila, K.-J. Bergstrand, S. Gustafsson, Biofilm Formation by Chlorella vulgaris is Affected by Light Quality, Current Microbiology 69 (2014) 699-702.

[18] A. Hodges, Z. Fica, J. Wanlass, J. VanDarlin, R. Sims, Nutrient and suspended solids removal from petrochemical wastewater via microalgal biofilm cultivation, Chemosphere 174 (2017) 46-48.

[19] B. Podola, T. Li, M. Melkonian, Porous Substrate Bioreactors: A Paradigm Shift in Microalgal Biotechnology?, Trends in Biotechnology 35 (2017) 121-132.

[20] C. Guo, D. Duan, Y. Sun, Y. Han, S. Zhao, Enhancing Scenedesmus obliquus biofilm growth and $\mathrm{CO} 2$ fixation in a gas-permeable membrane photobioreactor integrated with additional rough surface, Algal Research 43 (2019) 101620.

[21] D. Fischer, T. Bieber, Y. Li, H.-P. Elsässer, T. Kissel, A Novel Non-Viral Vector for DNA Delivery Based on Low Molecular Weight, Branched Polyethylenimine: Effect of Molecular Weight on Transfection Efficiency and Cytotoxicity, Pharmaceutical Research 16 (1999) 1273-1279.

[22] R. Namgung, J. Kim, K. Singha, C.H. Kim, W.J. Kim, Synergistic Effect of Low Cytotoxic Linear Polyethylenimine and Multiarm Polyethylene Glycol: Study of Physicochemical Properties and In Vitro Gene Transfection, Molecular Pharmaceutics 6 (2009) 1826-1835. 
[23] Y.-F. Chu, C.-H. Hsu, P.K. Soma, Y.M. Lo, Immobilization of bioluminescent Escherichia coli cells using natural and artificial fibers treated with polyethyleneimine, Bioresource Technology 100 (2009) 3167-3174.

[24] R. Karthikeyan, N. Krishnaraj, A. Selvam, J.W.-C. Wong, P.K.H. Lee, M.K.H. Leung, S. Berchmans, Effect of composites based nickel foam anode in microbial fuel cell using Acetobacter aceti and Gluconobacter roseus as a biocatalysts, Bioresource Technology 217 (2016) 113-120.

[25] J. Kramer, S. Soukiazian, S. Mahoney, J. Hicks-Garner, Microbial fuel cell biofilm characterization with thermogravimetric analysis on bare and polyethyleneimine surface modified carbon foam anodes, Journal of Power Sources 210 (2012) 122-128.

[26] C. Zamalloa, N. Boon, W. Verstraete, Decentralized two-stage sewage treatment by chemical-biological flocculation combined with microalgae biofilm for nutrient immobilization in a roof installed parallel plate reactor, Bioresource Technology 130 (2013) 152-160.

[27] C. Catto, L. De Vincenti, F. Cappitelli, G. D'Attoma, M. Saponari, F. Villa, F. Forlani, Non-Lethal Effects of N-Acetylcysteine on Xylella fastidiosa Strain De Donno Biofilm Formation and Detachment, Microorganisms 7 (2019).

[28] L. Zaouk, A. Massé, P. Bourseau, S. Taha, M. Rabiller-Baudry, S. Jubeau, B. Teychené, J. Pruvost, P. Jaouen, Filterability of exopolysaccharides solutions from the red microalga Porphyridium cruentum by tangential filtration on a polymeric membrane, Environmental Technology (2018) 1-18. 
[29] C.J. Van Oss, R.J. Good, M.K. Chaudhury, The role of van der Waals forces and hydrogen bonds in "hydrophobic interactions" between biopolymers and low energy surfaces, Journal of Colloid and Interface Science 111 (1986) 378-390.

[30] D. Vandamme, S. Eyley, G. Van den Mooter, K. Muylaert, W. Thielemans, Highly charged cellulose-based nanocrystals as flocculants for harvesting Chlorella vulgaris, Bioresource Technology 194 (2015) 270-275.

[31] Y. Yang, L. Xu, W. Zhu, L. Feng, J. Liu, Q. Chen, Z. Dong, J. Zhao, Z. Liu, M. Chen, One-pot synthesis of pH-responsive charge-switchable PEGylated nanoscale coordination polymers for improved cancer therapy, Biomaterials 156 (2018) $121-133$.

[32] Z. Ouyang, Z. Huang, X. Tang, C. Xiong, M. Tang, Y. Lu, A dually charged nanofiltration membrane by $\mathrm{pH}$-responsive polydopamine for pharmaceuticals and personal care products removal, Separation and Purification Technology 211 (2019) 90-97.

[33] S. Ge, P. Champagne, H. Wang, P.G. Jessop, M.F. Cunningham, Microalgae Recovery from Water for Biofuel Production Using CO2-Switchable Crystalline Nanocellulose, Environmental Science \& Technology 50 (2016) 7896-7903.

[34] Y.-Y. Yuan, C.-Q. Mao, X.-J. Du, J.-Z. Du, F. Wang, J. Wang, Surface Charge Switchable Nanoparticles Based on Zwitterionic Polymer for Enhanced Drug Delivery to Tumor, Advanced Materials 24 (2012) 5476-5480.

[35] Y. Luo, P. Le-Clech, R.K. Henderson, Simultaneous microalgae cultivation and wastewater treatment in submerged membrane photobioreactors: A review, Algal 
Research 24 (2017) 425-437.

[36] M. Horch, A.F. Pinto, M.A. Mroginski, M. Teixeira, P. Hildebrandt, I. Zebger, Metal-induced histidine deprotonation in biocatalysis? Experimental and theoretical insights into superoxide reductase, RSC Advances 4 (2014) 54091-54095.

[37] X. Wei, X. Bao, J. Wu, C. Li, Y. Shi, J. Chen, B. Lv, B. Zhu, Typical pharmaceutical molecule removal behavior from water by positively and negatively charged composite hollow fiber nanofiltration membranes, RSC Advances 8 (2018) 10396-10408.

[38] A.K. Hołda, I.F.J. Vankelecom, Understanding and guiding the phase inversion process for synthesis of solvent resistant nanofiltration membranes, Journal of Applied Polymer Science 132 (2015).

[39] L. Marbelia, A. Ilyas, M. Dierick, J. Qian, C. Achille, R. Ameloot, I.F.J. Vankelecom, Preparation of patterned flat-sheet membranes using a modified phase inversion process and advanced casting knife construction techniques, Journal of Membrane Science 597 (2020) 117621.

[40] Z. Zhao, A. Ilyas, K. Muylaert, I.F.J. Vankelecom, Optimization of patterned polysulfone membranes for microalgae harvesting, Bioresource Technology 309 (2020) 123367.

[41] Z. Zhao, P. Liu, S. Wang, S. Ma, J. Cao, Combustion characteristics and kinetics of five tropic oilgal strains using thermogravimetric analysis, Journal of Thermal Analysis and Calorimetry 131 (2018) 1919-1931.

[42] Z. Zhao, M.A. Rasool, C. Chen, S. Ma, L. Wang, G. Huang, Identification and 
screening of multiple tropical microalgal strains for antioxidant activity in vitro, Food Bioscience 36 (2020) 100649.

[43] Z. Zhao, S. Ma, A. Li, P. Liu, M. Wang, Effects of Trophic Modes, Carbon Sources, and Salinity on the Cell Growth and Lipid Accumulation of Tropic Ocean Oilgae Strain Desmodesmus sp. WC08, Applied Biochemistry and Biotechnology 180 (2016) 452-463.

[44] L. Marbelia, A. Ilyas, M. Dierick, J. Qian, C. Achille, R. Ameloot, I.F.J. Vankelecom, Preparation of patterned flat-sheet membranes using a modified phase inversion process and advanced casting knife construction techniques, Journal of Membrane Science (2019) 117621.

[45] C. Van Goethem, M. Mertens, I.F.J. Vankelecom, Crosslinked PVDF membranes for aqueous and extreme pH nanofiltration, Journal of Membrane Science 572 (2019) 489-495.

[46] C. Van Goethem, M.M. Magboo, M. Mertens, M. Thijs, G. Koeckelberghs, I.F.J. Vankelecom, A scalable crosslinking method for PVDF-based nanofiltration membranes for use under extreme $\mathrm{pH}$ conditions, Journal of Membrane Science 611 (2020) 118274.

[47] M. Mertens, M. Quintelier, I.F.J. Vankelecom, Magnetically induced membrane vibration (MMV) system for wastewater treatment, Separation and Purification Technology 211 (2019) 909-916.

[48] L. Marbelia, M.R. Bilad, N. Bertels, C. Laine, I.F.J. Vankelecom, Ribbed PVCsilica mixed matrix membranes for membrane bioreactors, Journal of Membrane 
Science 498 (2016) 315-323.

[49] M.H.A. Michels, A.J. van der Goot, N.-H. Norsker, R.H. Wijffels, Effects of shear stress on the microalgae Chaetoceros muelleri, Bioprocess and Biosystems Engineering 33 (2010) 921-927.

[50] A. Dobrak-Van Berlo, I.F.J. Vankelecom, B. Van der Bruggen, Parameters determining transport mechanisms through unfilled and silicalite filled PDMS-based membranes and dense PI membranes in solvent resistant nanofiltration: Comparison with pervaporation, Journal of Membrane Science 374 (2011) 138-149.

[51] L. Marbelia, M. Mulier, D. Vandamme, K. Muylaert, A. Szymczyk, I.F.J. Vankelecom, Polyacrylonitrile membranes for microalgae filtration: Influence of porosity, surface charge and microalgae species on membrane fouling, Algal Research 19 (2016) 128-137.

[52] E.M.V. Hoek, G.K. Agarwal, Extended DLVO interactions between spherical particles and rough surfaces, Journal of Colloid and Interface Science 298 (2006) $50-58$.

[53] F. Wang, M. Zhang, W. Peng, Y. He, H. Lin, J. Chen, H. Hong, A. Wang, H. Yu, Effects of ionic strength on membrane fouling in a membrane bioreactor, Bioresour Technol 156 (2014) 35-41.

[54] F. Zhao, H. Chu, Y. Su, X. Tan, Y. Zhang, L. Yang, X. Zhou, Microalgae harvesting by an axial vibration membrane: The mechanism of mitigating membrane fouling, Journal of Membrane Science 508 (2016) 127-135.

[55] L. Li, Z. Wang, L.C. Rietveld, N. Gao, J. Hu, D. Yin, S. Yu, Comparison of the 
Effects of Extracellular and Intracellular Organic Matter Extracted From Microcystis aeruginosa on Ultrafiltration Membrane Fouling: Dynamics and Mechanisms, Environmental Science \& Technology 48 (2014) 14549-14557.

[56] W. Huang, H. Chu, B. Dong, Understanding the fouling of algogenic organic matter in microfiltration using membrane-foulant interaction energy analysis: Effects of organic hydrophobicity, Colloids and Surfaces B: Biointerfaces 122 (2014) 447-456.

[57] B. Derjaguin, Untersuchungen über die Reibung und Adhäsion, IV, Kolloid-Zeitschrift 69 (1934) 155-164.

[58] H. Shi, L. Xue, A. Gao, Y. Fu, Q. Zhou, L. Zhu, Fouling-resistant and adhesion-resistant surface modification of dual layer PVDF hollow fiber membrane by dopamine and quaternary polyethyleneimine, Journal of Membrane Science 498 (2016) 39-47.

[59] N.G.P. Chew, S. Zhao, C. Malde, R. Wang, Superoleophobic surface modification for robust membrane distillation performance, Journal of Membrane Science 541 (2017) 162-173.

[60] B.-K. Chen, C.-T. Su, M.-C. Tseng, S.-Y. Tsay, Preparation of Polyetherimide Nanocomposites with Improved Thermal, Mechanical and Dielectric Properties, Polymer Bulletin 57 (2006) 671-681.

[61] Z. Zhao, A. Ilyas, K. Muylaert, I.F.J. Vankelecom, Optimization of patterned polysulfone membranes for microalgae harvesting, Bioresource Technology (2020) 123367. 
[62] H. Cao, O. Habimana, A.J.C. Semião, A. Allen, R. Heffernan, E. Casey, Understanding particle deposition kinetics on NF membranes: A focus on micro-beads and membrane interactions at different environmental conditions, Journal of Membrane Science 475 (2015) 367-375.

[63] J.H. Kim, P.-H. Choung, I.Y. Kim, K.T. Lim, H.M. Son, Y.-H. Choung, C.-S. Cho, J.H. Chung, Electrospun nanofibers composed of poly( $\varepsilon$-caprolactone) and polyethylenimine for tissue engineering applications, Materials Science and Engineering: C 29 (2009) 1725-1731.

[64] S.F. D'Souza, J.S. Melo, Immobilization of bakers yeast on jute fabric through adhesion using polyethylenimine: application in an annular column reactor for the inversion of sucrose, Process Biochemistry 36 (2001) 677-681.

[65] M. Christwardana, D. Frattini, G. Accardo, S.P. Yoon, Y. Kwon, Effects of methylene blue and methyl red mediators on performance of yeast based microbial fuel cells adopting polyethylenimine coated carbon felt as anode, Journal of Power Sources 396 (2018) 1-11.

[66] Y.-J. Won, S.-Y. Jung, J.-H. Jang, J.-W. Lee, H.-R. Chae, D.-C. Choi, K. Hyun Ahn, C.-H. Lee, P.-K. Park, Correlation of membrane fouling with topography of patterned membranes for water treatment, Journal of Membrane Science 498 (2016) 14-19.

[67] Y.-J. Won, D.-C. Choi, J.H. Jang, J.-W. Lee, H.R. Chae, I. Kim, K.H. Ahn, C.-H. Lee, I.-C. Kim, Factors affecting pattern fidelity and performance of a patterned membrane, Journal of Membrane Science 462 (2014) 1-8. 
[68] M.R. Bilad, H.A. Arafat, I.F.J. Vankelecom, Membrane technology in microalgae cultivation and harvesting: A review, Biotechnology Advances 32 (2014) 1283-1300. [69] P. Bohutskyi, D.C. Kligerman, N. Byers, L.K. Nasr, C. Cua, S. Chow, C. Su, Y. Tang, M.J. Betenbaugh, E.J. Bouwer, Effects of inoculum size, light intensity, and dose of anaerobic digestion centrate on growth and productivity of Chlorella and Scenedesmus microalgae and their poly-culture in primary and secondary wastewater, Algal Research 19 (2016) 278-290.

[70] N.M. Franklin, J.L. Stauber, S.C. Apte, R.P. Lim, Effect of initial cell density on the bioavailability and toxicity of copper in microalgal bioassays, Environmental Toxicology and Chemistry 21 (2002) 742-751.

[71] B. Ji, W. Zhang, N. Zhang, J. Wang, G.A. Lutzu, T. Liu, Biofilm cultivation of the oleaginous microalgae Pseudochlorococcum sp, Bioprocess and Biosystems Engineering 37 (2014) 1369-1375.

[72] M. Gross, W. Henry, C. Michael, Z. Wen, Development of a rotating algal biofilm growth system for attached microalgae growth with in situ biomass harvest, Bioresource Technology 150 (2013) 195-201.

[73] A.C. Guedes, H.M. Amaro, R.D. Pereira, F.X. Malcata, Effects of temperature and $\mathrm{pH}$ on growth and antioxidant content of the microalga Scenedesmus obliquus, Biotechnology Progress 27 (2011) 1218-1224.

[74] M.L. Bartley, W.J. Boeing, B.N. Dungan, F.O. Holguin, T. Schaub, pH effects on growth and lipid accumulation of the biofuel microalgae Nannochloropsis salina and invading organisms, Journal of Applied Phycology 26 (2014) 1431-1437. 
[75] Y. Zheng, Y. Huang, Q. Liao, Q. Fu, A. Xia, X. Zhu, Impact of the accumulation and adhesion of released oxygen during Scenedesmus obliquus photosynthesis on biofilm formation and growth, Bioresource Technology 244 (2017) 198-205.

[76] P.J. Schnurr, O. Molenda, E. Edwards, G.S. Espie, D.G. Allen, Improved biomass productivity in algal biofilms through synergistic interactions between photon flux density and carbon dioxide concentration, Bioresource Technology 219 (2016) 72-79. [77] A.J. Paquette, C.E. Sharp, P.J. Schnurr, D.G. Allen, S.M. Short, G.S. Espie, Dynamic changes in community composition of Scenedesmus-seeded artificial, engineered microalgal biofilms, Algal Research 46 (2020) 101805.

[78] C. Brunot, L. Ponsonnet, C. Lagneau, P. Farge, C. Picart, B. Grosgogeat, Cytotoxicity of polyethyleneimine (PEI), precursor base layer of polyelectrolyte multilayer films, Biomaterials 28 (2007) 632-640.

[79] I. Yudovin-Farber, N. Beyth, E.I. Weiss, A.J. Domb, Antibacterial effect of composite resins containing quaternary ammonium polyethyleneimine nanoparticles, Journal of Nanoparticle Research 12 (2010) 591-603.

[80] T. He, V. Chan, Covalent layer-by-layer assembly of polyethyleneimine multilayer for antibacterial applications, Journal of Biomedical Materials Research Part A 95A (2010) 454-464.

[81] I.M. Helander, H.-L. Alakomi, K. Latva-Kala, T. Mattila-Sandholm, I. Pol, E.J. Smid, L.G.M. Gorris, A. von Wright, Characterization of the Action of Selected Essential Oil Components on Gram-Negative Bacteria, Journal of Agricultural and Food Chemistry 46 (1998) 3590-3595. 
[82] Y. Liu, R. Luo, F. Shen, L. Tang, J. Wang, N. Huang, Construction of mussel-inspired coating via the direct reaction of catechol and polyethyleneimine for efficient heparin immobilization, Applied Surface Science 328 (2015) 163-169.

[83] N. Kawabata, M. Nishiguchi, Antibacterial activity of soluble pyridinium-type polymers, Applied and Environmental Microbiology 54 (1988) 2532-2535.

[84] V. Kafil, Y. Omidi, Cytotoxic impacts of linear and branched polyethylenimine nanostructures in a431 cells, Bioimpacts 1 (2011) 23-30.

[85] Z. Zhao, B. Liu, A. Ilyas, M. Vanierschot, K. Muylaert, I.F.J. Vankelecom, Harvesting microalgae using vibrating, negatively charged, patterned polysulfone membranes, Journal of Membrane Science (2020) 118617. 